\title{
Keratoconus Management Guidelines
}

\author{
${ }^{1}$ Jorge L Alió, ${ }^{2}$ Alfredo Vega-Estrada, ${ }^{3}$ Pablo Sanz-Díez, ${ }^{4}$ Pablo Peña-García, ${ }^{5}$ María Luisa Durán-García, ${ }^{6}$ Miguel Maldonado \\ ${ }^{1}$ Ophthalmology Division, Miguel Hernández University, Elche, Alicante, Spain; VISSUM Corporation, Alicante, Spain \\ ${ }^{2}$ Honorary Collaborator, Ophthalmology Division, University Miguel Hernández, Elche, Alicante, Spain; VISSUM Corporation \\ Alicante, Spain \\ ${ }^{3-5}$ Ophthalmology Division, Miguel Hernández University, Elche, Alicante, Spain \\ ${ }^{6}$ Institute of Applied Ophthalmobiology (IOBA), University of Valladolid, Valladolid, Spain
}

Corresponding Author: Jorge L Alió, PhD, Research, Development and Innovation, VISSUM Corporation, Calle Cabañal, 103016 Alicante, Spain, e-mail: jlalio@vissum.com

This study was partly financed by a project of the Spanish Ministry of Economy and Competitiveness, the Carlos III Health Institute and the Cooperative Health Research Thematic Network on 'Age-related Eye Disease, Visual Quality and Quality-of-Life', sub-project 'Visual Quality' (RD07/0062); and another project of the Spanish Ministry for Economy and Competitiveness, the Carlos III Health Institute, the Cooperative Health Research Thematic Network 'Prevention, Early Detection and Treatment of Prevalent, Degenerative and Chronic Eye Diseases', sub-program 'Ocular Structures and Common Pathologies' (RD12/0034).

\section{ACKNOWLEDGMENTS}

We present this keratoconus management guideline in order to provide an update on the aims and indications of the various therapies used to treat keratoconus. It is an official guide from OFTARED (Ophthalmic Research Collaborative Thematic Network, RD12/0034/007), a network that currently represents the collective efforts of a large number of medical institutions. The aim of these institutions is to improve the practice of ophthalmology through clinical innovation, guided in its practical application by multicenter research methods that generate objective criteria for use. In this sense, this guide constitutes the amalgamation of what we have all learned about treating keratoconus over the past 8 years. A task that began with the first Thematic Network RD07/0062/0018 which was followed by the current OFTARED, RD12/0034/007. During this time, we have constructed a large keratoconus database that may well be the largest in Europe at this time (Iberia Keratoconus Database). The various exploratory methods available today for the diagnosis of keratoconus have been analyzed consecutively with a view to finding how we might gain a better understanding of how this corneal pathology develops, and then how best to treat it.

As a result of this joint effort by the Thematic Network, OFTARED-RETICS, a new keratoconus classification system based on visual acuity has been established as well as an improved method to indicate intracorneal segments based on corrected vision (published in Am J Ophthalmol 2013;155(3):575-584). Numerous studies by our multicenter working group have led to a better understanding of the behavior of this disease under different circumstances, and in particular how it responds to treatment using modern innovative corrective methods based on corneal molding and stiffening. Readers will also learn how our collective efforts have achieved an approach to treat a disease once thought to be rare and now very common in clinical practice, while remaining independent of commercial constraints.

We hope that this keratoconus management guideline will prove useful to you all. Many clinical researchers have dedicated great time and effort to create something that aims to serve all of us and that will help improve patient care and their prognosis.

I would like to thank all those involved in the development of this guideline, not just my colleagues and co-authors but also all members of the OFTARED-RETICS. I would especially like to mention the following members for their outstanding contribution:

Dr Rafael Barraquer from the Barraquer Ophthalmological Clinic, Dr Manuel Sadaba at the University Clinic Navarra, Dr Ramón Gutiérrez at the Hospital of Murcia. 


\section{SUMMARY OF CONTENTS}

1. Introduction: What We understand by Keratoconus?

1.1. Definition

1.2. Epidemiology

1.3. Etiology

1.4. Clinical Diagnosis

1.5. Conclusion

2. Clinical Diagnosis, Classification, Follow-up and Initial Approach for Patients with Keratoconus

2.1. Keratoconus Detection and Confirming Diagnosis
2.1.1. Anterior Corneal Topography
2.1.2. Importance of Posterior Corneal Surface
2.1.3. Corneal Aberrometry
2.1.4. Visual and Refraction Testing
2.1.5. Pachymetry
2.1.6. Slit-Lamp
2.1.7. Retinoscopy
2.1.8. Corneal Biomechanical Testing
2.1.9. Diagnostic Confirmation

2.2. Keratoconus Classification

2.2.1. RETICS Classification

2.3. Keratoconus Progression-Risk Factors

2.4. Initial Patient Orientation

3. Guidelines for Therapeutic Management

3.1. Keratoconus Management in Patients with Contact Lenses

3.1.1. Soft Contact Lenses

3.1.2. Rigid Gas Permeable Lenses

3.1.3. Hybrid Lenses

3.1.4. Scleral Lenses

3.1.5. Piggyback System

3.1.6. Fitting and Lens/Cornea Relationship

3.1.7. Complications

4. Corneal Collagen Cross-linking

4.1. Introduction

4.2. Mechanisms of Action

4.3. Surgical Techniques-Protocols

4.4. Modifications to the Standard Procedure

4.4.1. Reducing Postoperative Complications

4.4.2. Reducing Treatment Times

4.4.3. Facilitating Treatment in Cases of very Thin Corneas

4.5. Patient Selection: Indications and Contraindications

4.6. Effect of Cross-Linking on Cornea

4.7. Others uses of Cross-Linking

5. Indications of Intracorneal Ring Segments

5.1. Types of Intracorneal Segments

5.2. Surgical Procedure: Indication and Selection of ICRS Implants in Corneal Ectatic Disease

5.3. Advantages and Disadvantages of Intracorneal Segment Implants

6. Indications of Combined Intracorneal Segments and Cross-linking Therapy

7. Refractive Keratoconus Management

7.1. Stability Criteria

7.2. Phakic Lenses

7.2.1. Implantation Criteria

7.3. Excimer Laser Correction

8. Cataract Surgery in Patients with Keratoconus

8.1. Indications

9. Monitoring Keratoconus Progression 


\section{INTRODUCTION: WHAT WE UNDERSTAND BY KERATOCONUS?}

\subsection{Definition}

Keratoconus is a generally bilateral but asymmetric corneal ectasia, which involves thinning of the corneal thickness, gradual corneal protrusion and irregular astigmatism that is generally progressive and can reach elevated levels. ${ }^{1}$

Onset is normally during puberty with $75 \%$ of cases being diagnosed before the age of 25 years. It continues to progress until the third decade of life, after which progression often slows down. The severity of its progression is partly associated with how early it appears..$^{2-7}$

Although evidence on the influence of sex in onset and progression is inconsistent, there appears to be a higher tendency in males. ${ }^{3-5}$

\subsection{Epidemiology}

The prevalence of keratoconus in the Spanish population has not yet been fully investigated. A study conducted with data from a population in Vigo and Pontevedra (Galicia) estimated the prevalence of keratoconus in Spain at approximately 181 cases per 100,000 inhabitants, with it being twice as common in men as in women. ${ }^{8}$

Occurrence in the general population is low, between $4 / 1000$ and 6/1000. ${ }^{1}$ Others have reported a lower incidence (between 1 and 2.3/1000). ${ }^{9}$ According to other authors, the current incidence is $1 / 2000$ per year, ${ }^{2,9}$ and depends on the geographic region; though there are also studies supporting the fact that the prevalence is higher in zones with higher UV exposure or with a combination of genetic and environmental factors. ${ }^{11}$

From an epidemiological viewpoint, keratoconus appears most often as an isolated disorder. There are reports that indicate a higher prevalence in persons with Down syndrome (prevalence 10 to 300 times higher), ${ }^{12-14}$ with connective tissue disorders (Marfan syndrome, Lobstein dystrophy, mitral valve prolapse or Ehlers-Danlos syndrome) ${ }^{15}$ or when concurring with other disorders, such as Leber's congenital amaurosis. ${ }^{16}$ Also, in metabolic disorders, such as diabetes mellitus, decreases the odds of having more severe keratoconus. ${ }^{17}$

\subsection{Etiology}

Although the etiology of this corneal dystrophy is still unclear, genetic, environmental and lifestyle factors appear to be involved, but to what extent has yet to be established. We know that factors, such as atopy or rubbing of eyes are epidemiologically linked to the development of keratoconus. ${ }^{1}$ Collaborative longitudinal evaluation of keratoconus (CLEK) reported that $48.2 \%$ of patients with keratoconus vigorously rubbed both eyes and only $2.2 \%$ rubbed significantly only one. ${ }^{18}$ Microtrauma due to the rubbing of the eye in predisposed individuals has been postulated. This damages the epithelium, triggering cytokine release, myofibroblast differentiation and metalloprotease activation, causing inflammation and changes in the biomechanical strength of the cornea and thinning of corneal tissue leading to the ectatic process known as keratoconus. ${ }^{11}$

Keratoconus is generally defined as a noninflammatory corneal disease, though it has now been shown that inflammatory mechanisms play a major role in its development and progression.

\subsection{Clinical Diagnosis}

Regarding clinical manifestations, the first thing we find is unstable refraction usually consisting of myopia and astigmatism and variable visual acuity impairment. Normal visual acuity may exist, but only in the early keratoconus stages. Retinoscopic reflection reveals a 'scissoring' shadow, while the Charleux oil droplet is observed in the ophthalmoscopic examination. In moderate and advanced stages, the signs revealed by biomicroscopy include a more conspicuous Munson sign, stromal thinning toward the apex of the keratoconus, usually found at the bottom or inferotemporal area of the cornea, a Fleischer ring located in the area of the cone, breaks in the Bowman's membrane, Vogt's striae in the Descemet's membrane parallel to the meridian of the cone and, in severe cases, it may be accompanied by corneal hydrops (an important sign given that it involves small breaks in Descemet's membrane), and there could be deep opacities in the apex of the cone leaving subepithelial scars. ${ }^{10}$ 
Often the patient is symptom free until a relative advanced disease stage. It usually starts with the patient complaining of decreased visual acuity at all distances, which cannot be compensated by correction, as well as distortion of images. Photophobia, glare and eye irritation making contact lenses uncomfortable are often characteristic symptoms of the disease grade. .119-22 $^{-19}$

Keratoconus diagnosis is now based on very conclusive diagnostic methods, such as corneal topography, which we will refer to later. These methods not only allow clinical diagnosis, even at early disease grades, but also close monitoring of its progression and its quantification based on various numerical indexes. The latter contribute greatly to the diagnostic precision and the monitoring of the progression of this corneal disease.

Other ectatic corneal dystrophies, apart from keratoconus, which often also present with progressive stromal thinning, and considered in the differential keratoconus diagnosis, include keratoglobus, pellucid marginal degeneration or Terrien marginal degeneration. ${ }^{23}$ The differential diagnosis with these is straightforward, with few problems today thanks to advances in diagnostic technology.

\subsection{Conclusion}

Keratoconus is probably one of the most common so-called 'rare diseases'. Its prevalence is probably higher than that reported by the majority of studies if we take into account subclinical or forme fruste keratoconus. With improvements in diagnostic methods used today, we may well find a higher incidence in the coming years. We should also remember that this is a multifactorial disease, with genetic and other environmental components, whose mechanism of development still remains unclear. ${ }^{11}$

\section{REFERENCES}

1. Rabinowitz YS. Keratoconus. Surv Ophthalmol 1998;42(4):297-319.

2. Kennedy RH, Bourne WM, Dyer JA. A 48-year clinical and epidemiologic study of keratoconus. Am J Ophthalmol 1986;101:267-273.

3. Owens H, Gamble G. A profile of keratoconus in New Zealand. Cornea 2003;22:122-125.

4. Pouliquen Y, Forman MR, Giraud JP. Evaluation of the rapidity of progression of keratoconus by a study of the relationship between age when first detected and age at operation (author's transl). J Fr Ophthalmol 1981;4:219-221.

5. Ertan A, Muftuoglu O. Keratoconus clinical findings according to different age and gender groups. Cornea 2008;27:1109-1113.

6. Tuft SJ, Fitzke FW, Buckley RJ. Myopia following penetrating keratoplasty for keratoconus. Br J Ophthalmol 1992;76:642-645.

7. Zadnik K, Barr JT, Edrington TB, Everett DF, Jamenson M, McMahon TT, et al. Baseline findings in the CLEK Study. Invest Ophthalmol Vis Sci 1998;39:2537-2546.

8. García-Pérez, Ramón. Estudio retrospectivo sobre 290 casos de queratocono. Gaceta Óptica 2009;441.

9. Krachmer JH, Feder RS, Belin MW. Keratoconus and related non-inflammatory corneal thinning disorders. Surv Ophthalmol 1984;28:293-322.

10. Barbara A. Textbook on keratoconus: New Insights. In: Kymionis GD, Plaka AD, Kontadakis GA. Clinical signs and different diagnosis of keratoconus, Saxena R, editor. 1st ed. New Delhi, India: Jaypee Brothers Medical Publishers (P) Ltd.; 2012 (Chapter 6).

11. Barbara A. Textbook on keratoconus: New Insights. In: François M, Ancele E, Kontadakis BJ. Epidemiology of keratoconus. Saxena R, editor. 1st ed. New Delhi, India: Jaypee Brothers Medical Publishers (P) Ltd.; 2012 (Chapter 1).

12. Pierse D, Eustace P. Acute keratoconus in mongols. Br J Ophthalmol 1971;55:50-54.

13. Slusher MM, Laibson PR, Mulberger RD. Acute keratoconus in Down's syndrome. Am J Ophthalmol 1968;66:1137-1143.

14. Kenyon KR, Kidwell EJ. Corneal hydrops and keratoconus associated with mongolism. Arch Ophthalmol 1976;94:494-495.

15. Woodward EG, Morris MT. Joint hypermobility in keratoconus. Ophthalmic Physiol Opt 1990;10:360-362.

16. Elder MJ. Leber congenital amaurosis and its association with keratoconus and keratoglobus. J Pediat Ophthalmol Strabismus 1994;31:38-40.

17. Kuo IC, Broman A, Pirouzmanesh A, Melia M. Is there an association between diabetes and keratoconus? Ophthalmol 2006; 113:184-190.

18. Yeniad B, Alparslan N, Akarcay K. Eye rubbing as an apparent cause of recurrent keratoconus. Cornea 2009;28(4):477-479.

19. Romero-Jiménez M, Santodomingo-Rubido J, Wolffsohn JS. Keratoconus: a review. Cont Lens Anterior Eye 2010;33(4):157-166.

20. Zadnik K, Barr JT, Gordon MO, Edrington TB. Biomicroscopic signs and disease severity in keratoconus. Collaborative Longitudinal Evaluation of Keratoconus (CLEK) Study Group Cornea 1996;15(2):139-146.

21. Weed KH, MacEwen CJ, Giles T, Low J, McGhee CN. The Dundee University Scottish keratoconus study: demographics, corneal signs, associated diseases, and eye rubbing. Eye (Lond) 2008;22(4):534-541.

22. Sherwin T, Brookes NH. Morphological changes in keratoconus: pathology or phatogenesis. Clin Experiment Ophthalmol 2004; 32(2):211-217.

23. Amsler M. The 'forme fruste' of keratoconus (in German) Wien Klin Wochenschr 1961 Dec 8;73:842-843. 


\section{CLINICAL DIAGNOSIS, CLASSIFICATION, FOLLOW-UP AND INITIAL APPROACH FOR PATIENTS WITH KERATOCONUS}

\subsection{Keratoconus Detection and Confirming Diagnosis}

The following are key in confirming the diagnosis:

\subsubsection{Anterior Corneal Topography}

Anterior corneal topography is based on analyzing the image of the Placido disks as reflected by the cornea. ${ }^{1}$ This type of analysis is currently regarded as the primary method for the early diagnosis of keratoconus as it allows an accurate and simultaneous evaluation of the curvature radius at multiple points on the cornea. It detects any type of irregularity that may exist on the optical surface.

According to the Rabinowitz classification, ${ }^{2,3}$ there are three topographic groups:

- Group I-Symmetric patterns including round, oval and symmetric bow tie (Fig. 1).

- Group II-All other asymmetric patterns except asymmetric bow tie with misaligned hemi-meridians (skewed radical axes) (Fig. 2).

- Group III-Asymmetric bow tie with misaligned hemi-meridians. This is extremely rare in normal individuals and common in those with keratoconus (Fig. 3).

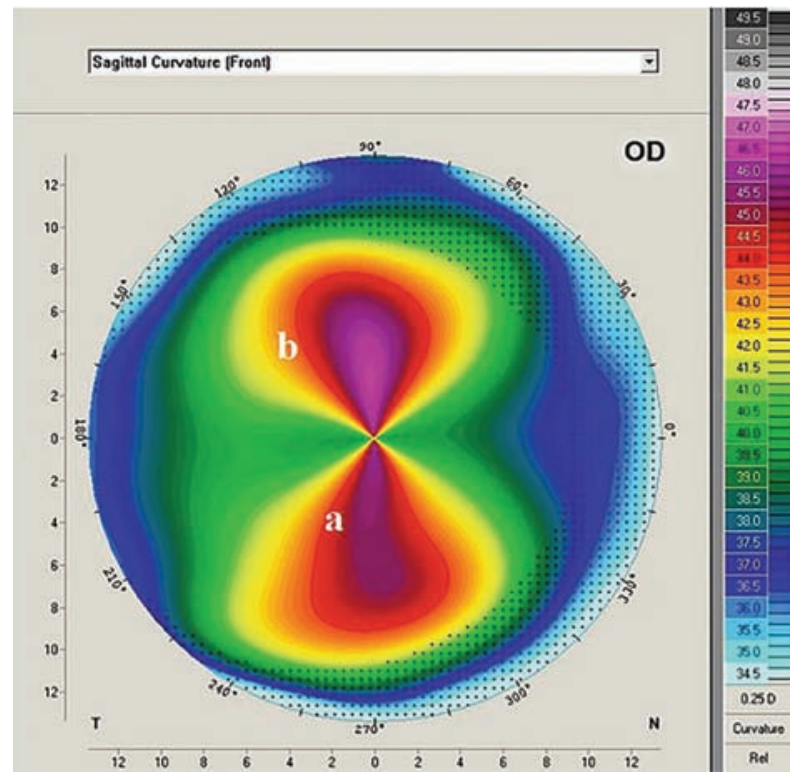

Fig. 1: Symmetric bow tie

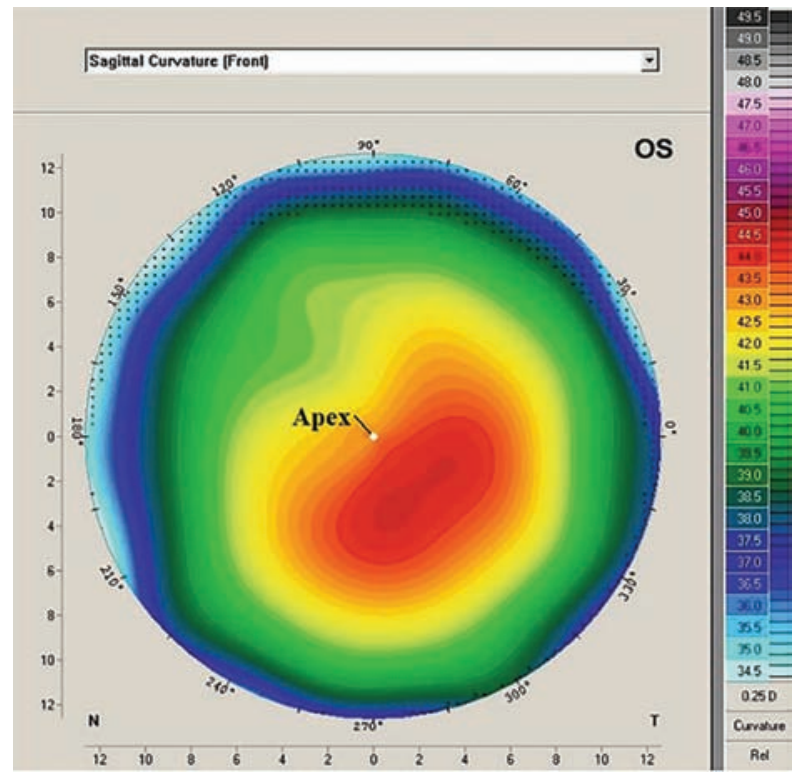

Fig. 2: Asymmetric pattern

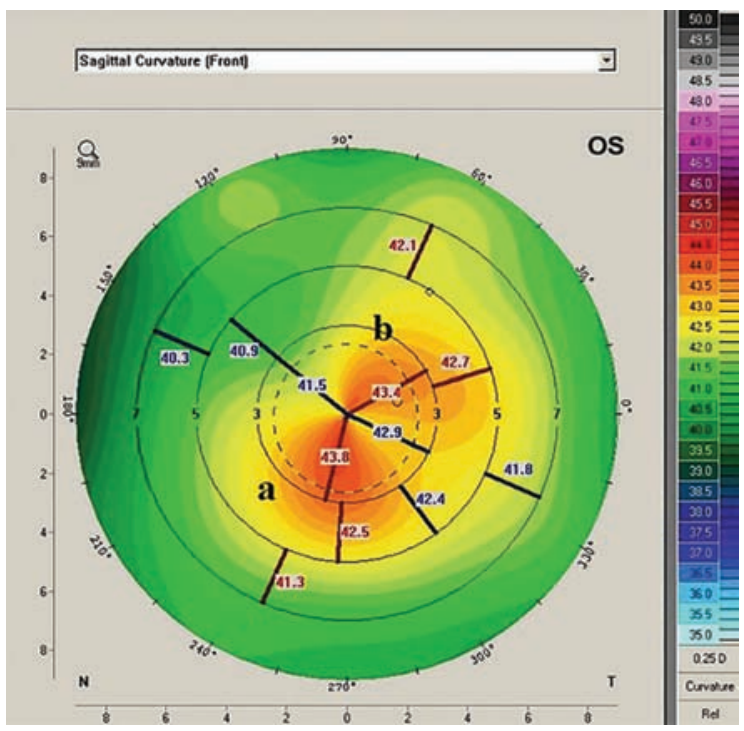

Fig. 3: Asymmetric bow tie 
Cone morphology is usually categorized into three types: oval, globus or nipple (when concentrated in a limited region). The location of the cones can be central, upper or lower and they are particularly common in the lower region, where cornea thinning and protrusion normally occur in ectatic processes. The point of maximum protrusion is the apex of the cone.

Current topographers provide a large quantity of useful parameters for the detection of keratoconus. The following are some of the most prominent keratoconus detection indices:

1. Simulated keratometry (Sim K): $:^{4}$ Provides the Diopter power of the flattest and steepest meridians (K1 and K2 respectively). It is usually calculated using the measurements of the intermediate rings ( 3 to 9 ) of the topographic image. Although this lacks high sensitivity or specificity in the diagnosis of keratoconus, it is used as a basis for other more appropriate parameters.

Values:

- Normal cornea: $43.53 \pm 1.02$ Diopter (D)

- Suspected keratoconus: Sim K > 45.57 D

This parameter alone is not very sensitive for the diagnosis of keratoconus.

2. Surface asymmetry index (SAI): ${ }^{5}$ Is the average difference between corresponding points $180^{\circ}$ apart on 128 equallyspaced meridians. A spherical surface corresponds to SAI $=0$. The higher the SAI, the higher the asymmetry.

3. Corneal irregularity measurement (CIM): ${ }^{6}$ Is a numerical value representing the degree of irregularity present on the corneal surface. This indicator quantifies the standard deviation between the cornea being measured and the toric reference surface. Therefore, it is a way of assessing irregular corneal astigmatism. The higher this index, the more likely it is that the cornea has a morphological abnormality. Corneal irregularity measurement values are classified as follows:

- Normal or healthy cornea: 0.03 to $0.68 \mu \mathrm{m}$

- Suspected keratoconus: 0.69 to $1.00 \mu \mathrm{m}$

- Diseased cornea: 1.10 to $5.00 \mu \mathrm{m}$.

4. Surface regularity index (SRI): $:^{7}$ Quantifies the regularity of the corneal surface in the central $4.5 \mathrm{~mm}$ diameter. It measures the differences in the power gradient between successive ring pairs in 256 equally-spaced meridians. As this index refers to the central corneal area, it correlates well with visual acuity values $(p=0.80, p<0.001)$. Values:

- Perfectly regular cornea: 0.5

- Normal or healthy cornea: $<0.56$.

5. Inferior-superior (I-S) asymmetry: ${ }^{8}$ Defined as the power difference between five points on the inferior hemisphere and five points on the superior hemisphere located $3 \mathrm{~mm}$ from the corneal apex, which are spaced at $30^{\circ}$ intervals. Values:

- Normal cornea: $<1.4 \mathrm{D}$

- Suspected keratoconus: Between 1.4 and $1.8 \mathrm{D}$

- Keratoconus: > $1.8 \mathrm{D}$

6. KISA index (\%): ${ }^{9}$ Developed by Rabinowitz as a tool for the early detection of keratoconus. Its sensitivity and specificity are high.

It is derived as the product of several indices:

- $\quad \mathrm{KISA}(\%)=\frac{\mathrm{K}(\mathrm{I}-\mathrm{S})(\mathrm{AST})(\mathrm{SRAX})}{300} \times 100$

- Central K: Mean corneal power

- I-S: Inferior-superior asymmetry index (as described above)

- AST: Degree of regular cornea astigmatism (Sim K2 - Sim K1)

- Skewed radial axis (SRAX): Quantifies irregular astigmatism through the misalignment between the most curved corneal hemi-meridians.

7. Keratoconus prediction index $(\mathrm{KPI}):^{3}$ This is defined by the following formula:

$\mathrm{KPI}=0.30+0.01^{*}\left(-41.23-0.15^{*} \mathrm{DSI}+1.18^{*} \mathrm{OST}+1.79^{*} \mathrm{CSI}+4.13^{*} \mathrm{SAI}-0.60^{*} \mathrm{Sim} \mathrm{K} 1+1.08 * \mathrm{Sim} \mathrm{K} 2-3.74^{*} \mathrm{IAI}\right.$ $\left.+0.10^{*} \mathrm{AA}\right)$

KPI values above 0.38 can be considered as pathological, with a sensitivity of 86 and 100\% specificity.

Simulated keratometry (Sim K): as previously defined. 
Differential sector index (DSI): Average power difference between $45^{\circ}$ sectors with the highest and lowest power.

Opposite sector index (OSI ): Average power difference between opposite $45^{\circ}$ sectors. ${ }^{11}$

Center-surround index CSI): Difference in the mean power between the central area $(3 \mathrm{~mm})$ and a mid-peripheral ring (3-6 mm).

Surface asymmetry index (SAI): As previously defined.

Irregular astigmatism index (IAI): Measures power variations along each semi-meridian, normalized by the mean corneal power and the number of points considered.

Analyzed area $(A A)$ : Is the ratio of the interpolated data area to the area circumscribed by the most peripheral ring.

8. [Keratoconus classification index (KCI) or Klyce-Maeda method]: ${ }^{10}$ Designed for TMS-1 topography. An expert system that combines the KPI with a binary decision tree for its calculation. The KPI is combined with other indices (DSI, OSI, CSI, Sim K2) in reaching the decision. An 89\% sensitivity and a 99\% specificity have been described. Its measurement is expressed as a percentage, and the higher the percentage the more compatible The topographic pattern with that of keratoconus.

9. Keratoconus severity index (KSI) ${ }^{1,3}$ Also known as Klyce-Smolek neural network. It allows the presence or absence of keratoconus to be detected, as well as its grading (mild, moderate or advanced). It has also been developed for TMS-1 topography: Values:

- Normal: $<15 \%$

- Suspected keratoconus: Between 15 and 30\%

- Keratoconus: $>30 \%$.

\subsubsection{Importance of Posterior Corneal Surface}

Conventional topography of the anterior surface of the cornea is, as mentioned, an important keratoconus diagnostic tool, though it also has certain limitations. To circumvent these, the latest generation topographers include a detailed analysis of the posterior corneal surface. These are based on the combination of two devices: Placido rings and a Scheimpflug camera. They also provide pachymetry mapping of the cornea.

Evaluating the posterior corneal surface has become a standard keratoconus diagnostic method in current topography. Some authors have even reported that keratoconus begins to develop in the posterior cornea before manifesting in the anterior, though there is no consensus in this respect. ${ }^{12}$ In any case, it has been demonstrated that normally the area of greatest corneal protrusion and thinning usually coincides quite well with the area of greatest optical power both in the anterior and posterior surface of the cornea. An aspherotoric surface, when used as a reference, improves the information of the posterior surface in relation to the best fit sphere.

Recent studies show that taking the diagnostic indices of both corneal surfaces into account significantly improves the sensitivity and specificity of keratoconus diagnosis. ${ }^{13,14}$

\subsubsection{Corneal Aberrometry}

Aberrometry techniques allow an ideal wavefront (not affected by aberrations) to be compared against that obtained when said ideal front crosses an optical surface. The wavefront obtained in this way will always be affected, to some extent, by optical aberrations. The distances between the various points of both wavefronts are used to quantify the aberrations induced by the optical surface crossed. Measuring these aberrations allow an objective assessment of the quality of the image that an optical system may form.

Use of the information obtained from ocular and corneal aberrometry is currently extensive and is of special importance in the detection of diseases, such as keratoconus.

Due to the irregular corneal surface characteristic of this disease, there is an increase in corneal (and ocular) optical higher-order aberrations. It is of particular importance to note the presence of high comatic aberration values. Primary comatic values between 0.5 and 1.0 microns are compatible with initial keratoconus grades. As we will see later (according to the Alió-Shabayek classification), coma-like aberrations between 1.50 and 2.50 microns are characteristic of grade I keratoconus.

Furthermore, high trefoil values (from 0.1 microns) have been identified as suspected keratoconus values. Thus, as mentioned previously, higher-order aberrations above the mean values could alert us to the presence of keratoconus. 
As mentioned above, examining the posterior cornea is critical in the ectatic cornea because the more irregular its surface, the higher the possibility of astigmatism induced by this posterior surface. Up to now, only the anterior surface of the cornea has been used to analyze aberrations since posterior surface data are not entirely consistent, and there is insufficient scientific evidence analyzing the effect of posterior astigmatism in the overall astigmatism in these cases.

\subsubsection{Visual and Refraction Testing}

Due to optical aberrations resulting from topographical corneal anomalies, these patients usually have high irregular astigmatism values, and also often present moderate to high myopia. The principal refractive sign is failure to achieve complete optical compensation of ametropia with spherocylindrical lenses. Therefore, corrected visual acuity for these patients will be lower than that in patients with no corneal disease. Hence, corrected visual acuity has been used in the RETICS scale ${ }^{15,16}$ (as described below) to determine the keratoconus severity grade; not only in terms of its functional implications, but also because it is directly associated with the level of corneal irregularity. Of course, vision with no optical compensation will be lower than that of a healthy eye with similar ametropia.

\subsubsection{Pachymetry}

Pachymetry (ultrasonic or optical) is another important test in screening for keratoconus and quantifying its progression. Keratoconus involves a progressive loss of corneal thickness, thus low pachymetry may constitute a sign indicative of keratoconus. We should remember that normality is established at approximately 550 micron thickness, although this value depends on the system used to measure it. Not all the measurements used are fully interchangeable.

\subsubsection{Slit-Lamp}

This test is useful above all to detect signs characteristic of advanced keratoconus, such as the presence of Vogt's striae and Fleischer ring (Figs $4 \mathrm{~A}$ to $\mathrm{C}$ ). Thus early detection of this disease is not feasible.

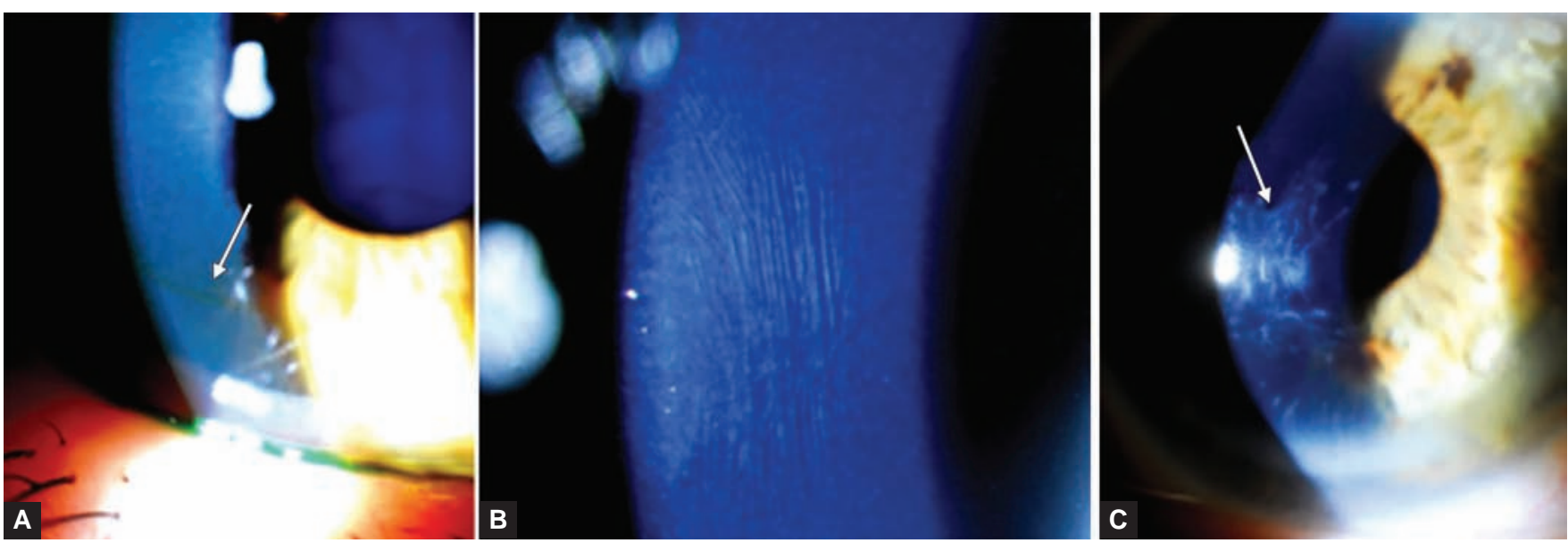

Figs 4A to C: Signs of advanced keratoconus: (A) Fleischer ring, (B) Vogt's striae and (C) Scars in apex of cone

\subsubsection{Retinoscopy}

During retinoscopy in patients with moderate-advanced keratoconus it is impossible to accurately locate the principal meridians, because they do not exist due to corneal irregularity. Also, 'scissoring shadows', very characteristic of the keratoconus eye, are also observed.

\subsubsection{Corneal Biomechanical Testing}

At present, there are two devices available on the market that provide information on the corneal biomechanical response: Ocular response analyzer (ORA) (Reichter, Buffalo, NY) and Corvis ST (Oculus, Germany). Both are 
non-contact tonometers. The first is more widely used and predicts two principal parameters: corneal hysteresis $(\mathrm{CH})$ and a parameter called corneal resistance factor (CRF) associated with the corneal resistance to deformation. The lower these values, the higher the mechanical corneal deterioration. Normal values of $10.8 \pm 1.5 \mathrm{~mm} \mathrm{Hg}$ have been described for $\mathrm{CH}$ and $11.0 \pm 1.6 \mathrm{~mm} \mathrm{Hg}$ for $\mathrm{CRF}^{17}$

These are not considered as devices that offer great diagnostic reliability. There is a substantial zone of diagnostic uncertainty and neither has demonstrated sufficient intra- or inter-individual repeatability in the measurements. However, they may serve as a complementary test when it comes to confirming a diagnosis. ${ }^{22}$

\subsubsection{Diagnostic Confirmation}

It ought to be pointed out that none of these diagnostic tests are $100 \%$ conclusive in the detection of keratoconus. Thus the importance of confirming the presence of various characteristic signs at the same time in order to conclude that it is indeed a case of keratoconus. Also, it is worth stressing that the regular conduct of these tests is essential to confirm the existence or not of the disease in cases of doubt; and to distinguish it from cases that simply deviated from the normal without being pathological, or cases where the disease only partially develops then stops for whatever reason without progressing to manifest keratoconus. These latter cases are known as forme frustre keratoconus, as development of the disease has been frustrated.

As we have seen already there are several diagnostic indices and, evidently, it is complicated for clinicians to take them all into account at the same time when making a decision. This is particularly true in suspected cases (subclinical and forme frustre). ${ }^{21}$

Furthermore, the diagnosis of these forms is of special importance as cases for which corneal refractive surgery would be unsuited could be identified.

To facilitate the diagnosis of these cases, ever-increasingly complex algorithms are being developed that allow high sensitivity and specificity to be obtained. These include those published by Saad and Gatinel ${ }^{23}$ or Ambrosio and Belin ${ }^{24}$ where tomographic and topographic parameters are used to increase the diagnostic sensitivity in cases of suspected keratoconus forms.

The neural network recently developed by Smadja et $\mathrm{a}^{13}$ for the Galilei topographer seems to us to be particularly relevant. This topographer allows both the anterior and posterior corneal surfaces to be measured. Although the software is capable of analyzing 55 different variables, it has been verified that those with the greatest sensitivity and specificity are the asphericity asymmetry index (AAI), corneal volume and I-S (inferior-superior asymmetry index). The following shows the total and pruned decision trees for the differentiation between eyes with manifest keratoconus and normal eyes (Fig. 5) and for the differentiation between eyes with subclinical keratoconus and normal eyes (Fig. 6).
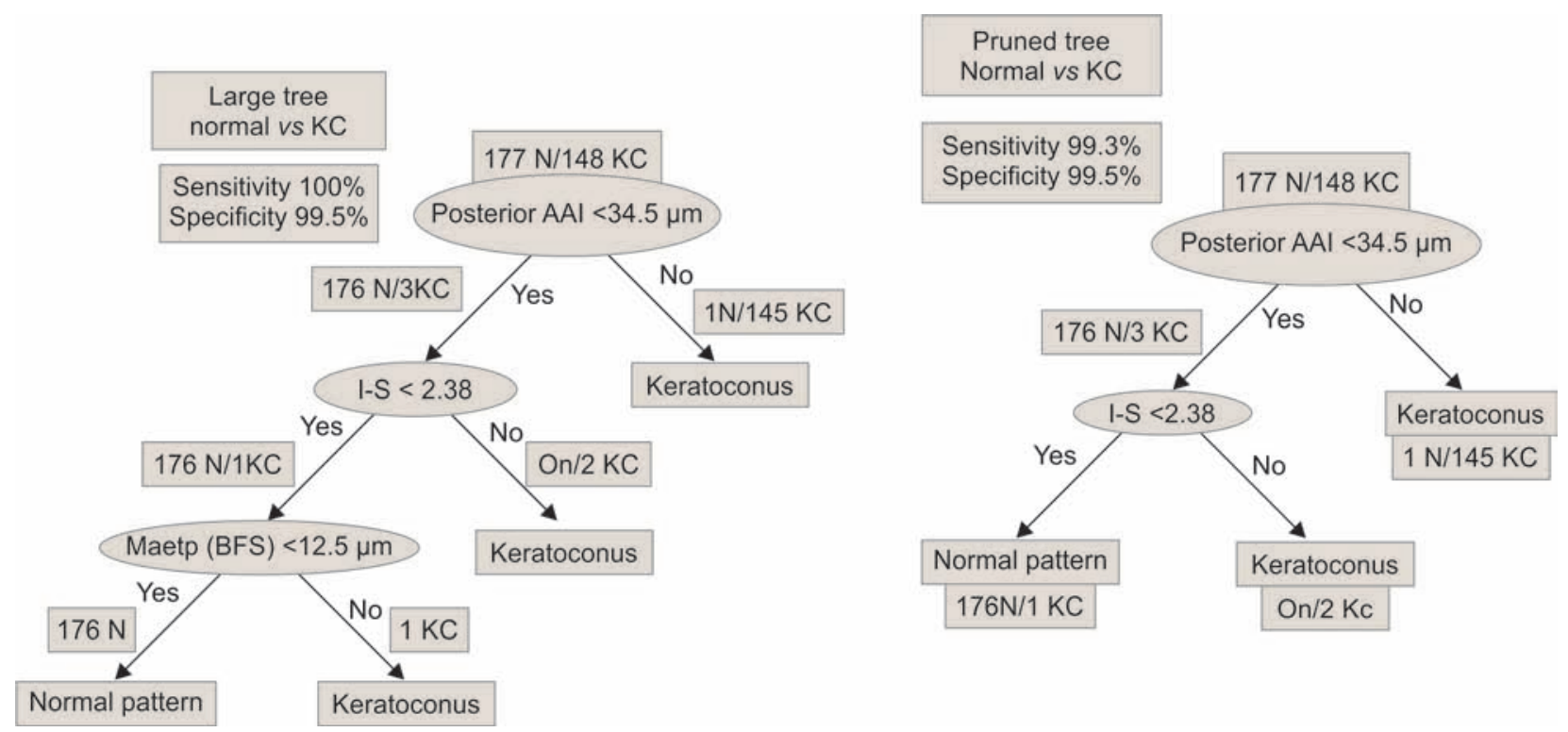

Fig. 5: Total and pruned decision trees to discriminate between normal eyes and eyes with manifest keratoconus ${ }^{13}$ 


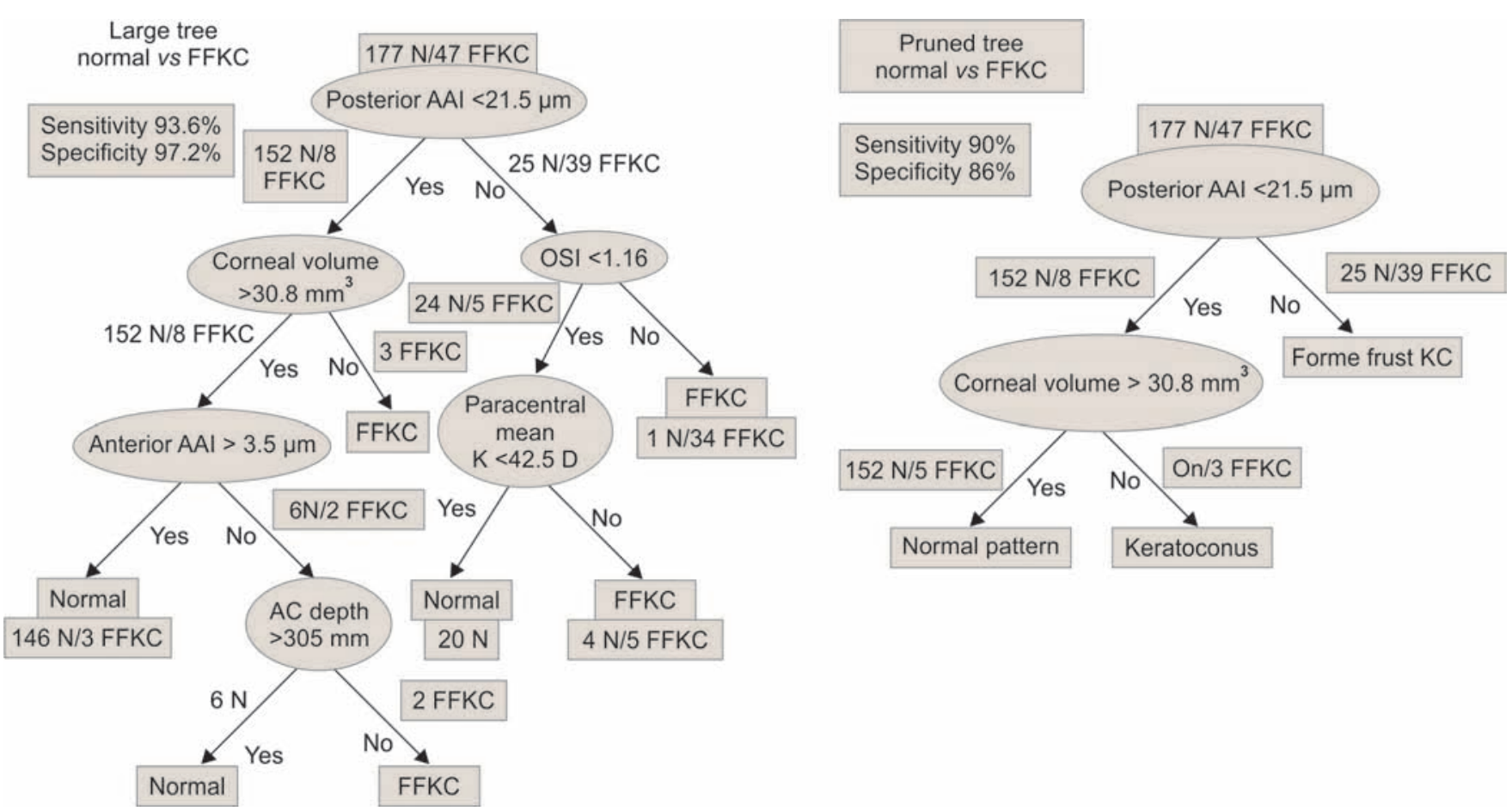

Fig. 6: Total and pruned decision trees to discriminate between normal eyes and eyes with subclinical keratoconus ${ }^{13}$

Despite progress in the development of intelligent systems that enable automatic diagnosis, we believe that a comprehensive analysis of all the information gathered in the above tests by an experienced clinician is essential in order to make the most reliable diagnosis possible.

\subsection{Keratoconus Classification}

Due to the great variability among patients with keratoconus, it is very important to grade this disease in order to provide some general guidance for the clinician regarding the level of progression and the treatment options that can be offered.

There are various keratoconus classifications depending on which principal factors are considered. Traditionally, the most widely used classification is the Amsler-Krumeich (1946) scale. ${ }^{21}$ This scale is based primarily on keratometric criteria but also includes other factors, such as refraction and pachymetry. The grades are:

- Grade 1

- Eccentric steepening

- Mean keratometric readings < $48.00 \mathrm{D}$

- Myopia and astigmatism less than $5.00 \mathrm{D}$

- Grade 2

- Mean keratometric readings: 48.00 to $53.00 \mathrm{D}$

- Myopia and astigmatism between 5.00 and $8.00 \mathrm{D}$

- Absence of scaring or striae

- Pachymetry $>400$ microns at point of most thinning

- Grade 3

- Mean keratometric readings: 53.00 to $55.00 \mathrm{D}$

- Myopia and astigmatism between 8.00 and 10.00 D

- Absence of scaring or striae

- Pachymetry between 300 and 400 microns at point of most thinning

- Grade 4

- Mean keratometric readings: > 55.00 D

- Refraction not measurable

- Striae or scarring

- Pachymetry between 200 and 300 microns at point of most thinning 
Following the advances in topographic methods, capable of providing corneal aberrometric data, the AlióShabayek scale (2006) was developed. ${ }^{18}$ This scale is better suited to current diagnostic methods. In addition to the factors mentioned previously, it includes aberrometry of the anterior surface of the cornea, with special emphasis on comatic aberrations. These parameters are used because coma-like aberration values (and generally higher-order aberrations) tend to increase with increasing protrusion of the cone, and hence with disease progression. This classification establishes the following grades:

- Grade 1

- Mean central keratometric reading: Less than or equal to $48.00 \mathrm{D}$

- $\quad$ RMS of coma-like aberrations: Between 1.50 and $2.50 \mu \mathrm{m}^{*}$

- Absence of scaring or striae

- Grade 2

- Mean central keratometric readings: Between 48.00 and 53.00 D

- RMS of coma-like aberrations: Between 2.50 and $3.50 \mu \mathrm{m}$

- Absence of scaring or striae

- Pachymetry over 400 microns at point of most thinning

- Grade 3

- Mean central keratometric readings: Between 53.00 and 55.00 D

- RMS of coma-like aberrations: Between 3.50 and $4.50 \mu \mathrm{m}$

- Absence of scaring or striae

- Pachymetry between 300 and 400 microns at point of most thinning

- Grade 4

- Mean keratometric readings: Over 55.00 D

- $\quad$ RMS of coma-like aberrations: Over $4.50 \mu \mathrm{m}$

- Striae or scarring

- Pachymetry between 200 and 300 microns at point of most thinning

*RMS: root mean square. Refers to the quadratic mean of the Zernike coefficients corresponding to a particular aberration.

\subsubsection{RETICS Classification ${ }^{15,16}$}

As a result of the multicenter cooperative work by the thematic network, a functional scale based primarily on corrected distance visual acuity (CDVA) was finally developed and titled the RETICS classification. ${ }^{15,16}$ So far, many classification systems have been proposed in order to determine the severity of the corneal ectatic disease but most have been developed taking into consideration the topographical morphology of the disease without considering other clinical variables that are closely related to the patient's visual function. For this reason, the classification system we use determines the severity of the disease, taking into account functional and not purely geometric parameters. Variables presenting a highly significant correlation, such as the internal astigmatism, comma-like RMS, mean central keratometry, asphericity at $8 \mathrm{~mm}$ of corneal diameter are considered, and which are also directly related to the degree of visual limitation.

The main features of this classification are:

- Grade 1

- CDVA: > 0.9 (decimal)

- Internal astigmatism: Between 1.59 and 2.14 D

- $\quad$ RMS of coma-like: Between 1.16 and $1.52 \mu \mathrm{m}$

- Mean central keratometric readings: Between 44.75 and 45.40 D

- Q8mm: Between -0.22 and -0.05

- Pachymetry: Between 495 and $510 \mu \mathrm{m}$

- Grade 2

- $\quad 0.6<$ CDVA $\leq 0.9$

- Internal astigmatism: Between 2.18 and $2.79 \mathrm{D}$

- $\quad$ RMS of coma-like: Between 1.82 and $2.31 \mu \mathrm{m}$

- Mean central keratometric readings: Between 46.03 and 46.93 D 
- $\mathrm{Q}_{8 \mathrm{~mm}}$ : Between -0.48 and -0.22

- Pachymetry: Between 475 and $493 \mu \mathrm{m}$

- Grade 3

- $\quad 0.4<$ CDVA $\leq 0.6$

- Internal astigmatism: Between 3.04 and 4.17

- RMS of coma-like: Between 2.65 and $3.32 \mu \mathrm{m}$

- Mean central keratometric readings: Between 48.21 and 49.27 D

- $\mathrm{Q}_{8 \mathrm{~mm}}$ : Between -0.95 and -0.58

- Pachymetry: Between 451 and $470 \mu \mathrm{m}$

- Grade 4

- $\quad$ CDVA $\leq 0.4$

- Internal astigmatism: Between 3.68 and $4.58 \mathrm{D}$

- $\quad$ RMS of coma-like: Between 3.45 and $4.42 \mu \mathrm{m}$

- Mean central keratometric readings: Between 51.42 and 53.12 D

- $\mathrm{Q}_{8 \mathrm{~mm}}$ : Between -1.21 and -0.83

- Pachymetry between 433 and $454 \mu \mathrm{m}$

- Corneal striae or scarring in $60 \%$ of cases

- Grade PLUS

- CDVA $<0.2$

- Internal astigmatism: Over $5.50 \mathrm{D}$

- $\quad$ RMS of coma-like: Over $5.50 \mu \mathrm{m}$

- Mean central keratometric readings: Over $57.00 \mathrm{D}$

- $\mathrm{Q}_{8 \mathrm{~mm}}$ : Less than -1.50

- Pachymetry between 360 and $420 \mu \mathrm{m}$

- Striae or scarring

*RMS: Root mean square refers to the quadratic mean of the Zernike coefficients corresponding to a particular aberration. $Q_{8 \mathrm{~mm}}$ : corneal asphericity at $8 \mathrm{~mm}$. Limits of corrected visual acuity are defined by the four quartiles. All defined ranges for the other variables at $95 \%$ confidence.

In papers by the Thematic Network focusing on the visual success of surgical treatment of keratoconus, we used the RETICS scale as our guide, since it is more suitable for these purposes. Table 1 shows an outline of the grades of the RETICS scale. ${ }^{15,16}$

\subsection{Keratoconus Progression-Risk Factors}

The following have been identified as factors affecting the progression of keratoconus: ${ }^{19,20}$

a. Genetic factors: Although family history may be influential in terms of incidence, it is interesting to note that there is no evidence that this affects how quickly the disease evolves.

b. Age at which the disease is detected: So far the earlier the disease is manifest, the more rapid the progression.

c. Presence of diseases, such as Down's syndrome has also been identified as clearly predisposing progression of keratoconus.

d. Race also affects progression (Caucasians have the lowest rate of progression once the disease is detected).

e. Changes occurring due to chronic inflammation of the ocular surface (such as severe allergic conjunctivitis) are also generally taken as a poor prognosis (possibly due to more rubbing of eyes).

f. Corneal curvature: The higher the curvature, the greater the speed of progression.

g. High corneal cylinders: Corneal cylinder over 1.9 D represents a poor prognosis in terms of disease progression.

$\mathrm{h}$. The presence of keratoconus in one eye is also a clearly influential factor in the development of this disease in the contralateral eye.

\subsection{Initial Patient Orientation}

Although at present the developing of new techniques to treat keratoconus has allowed significant improvements in the quality-of-life expectations for patients, we must remember that we are still far from finding a 'solution' or definitive treatment for keratoconus. 


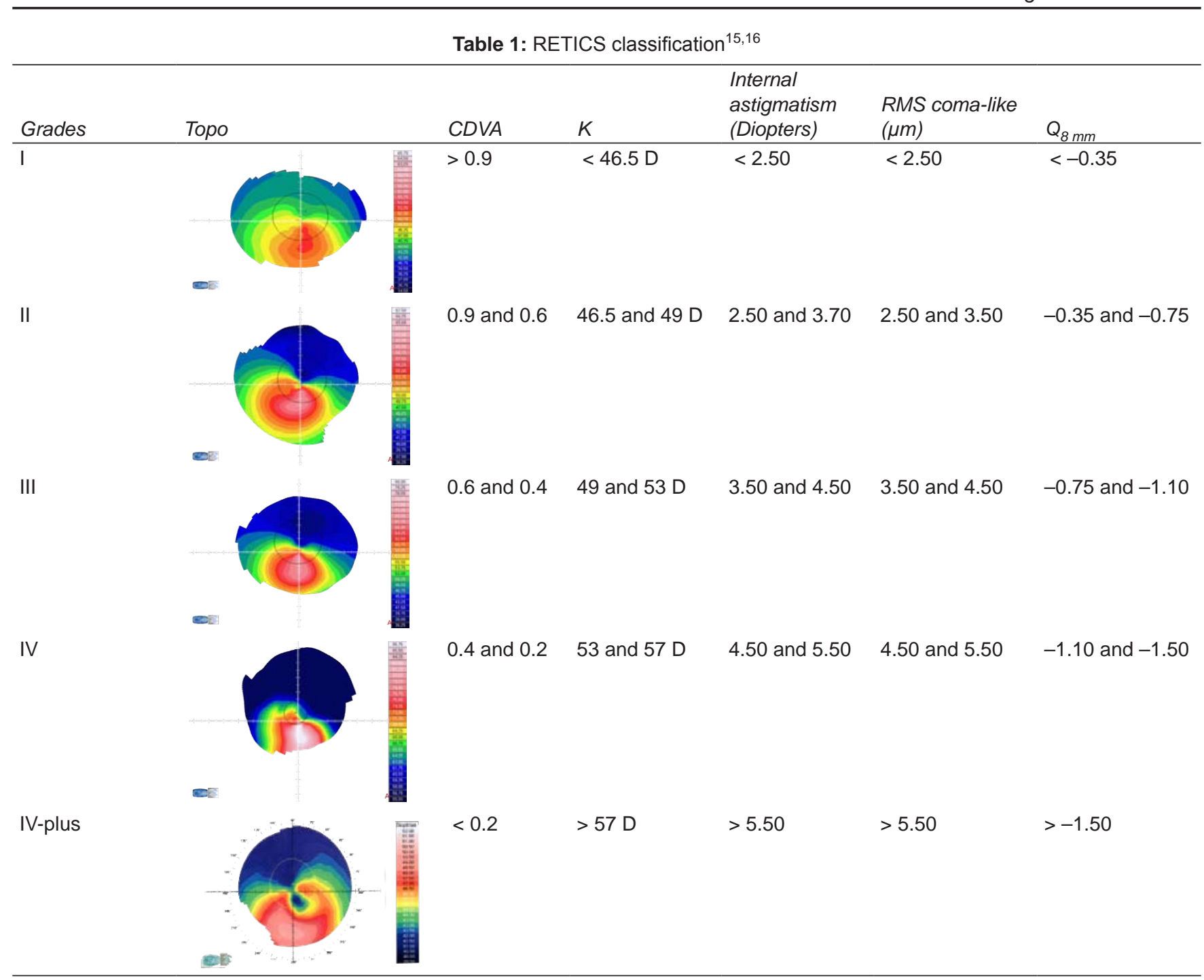

We must explain to the patient that this is a progressive disease in the vast majority of cases, particularly in young patients, and try to guide them about the possibilities in terms of treatment and lifestyle changes, such as avoiding rubbing of eyes or treating chronic ocular inflammatory diseases, such as allergic conjunctivitis. As there is currently a relatively large array of treatment possibilities, many of which can be combined, it is particularly important to clarify the potential risks and benefits of each treatment as applicable to each individual case.

Because of major inter-individual variability in treatment responses, the right choice is not always straightforward, and hence, the need for this guide.

\section{REFERENCES}

1. Keller PR, van Sarrloos PP. Perspectives on corneal topography: a review of videokeratoscopy. Clin Exp Optom 1997;80:1:18-30.

2. Rabinowitz YS, Yang H, Brickman Y, Akkina J, Riley C, Rotter JI, Elashoff J. Videokeratography database of normal human corneas. Br J Ophthalmol 1996;80(7):610-616.

3. Li X, Rabinowitz YS, Rasheed K, Yang H. Longitudinal study of the normal eyes in unilateral keratoconus patients. Ophthalmol 2004;11(3):440-446.

4. Smolek MK, Klyce SD. Current keratoconus detection methods compared with a neural network approach. Invest Ophthalmol Vis Sci 1997 Oct;38(11):2290-2299.

5. Dingeldein SA, Klyce SD, Wilson SE. Quantitative descriptors of corneal shape derived from computer-assisted analysis of photokeratographs. Refract Corneal Surg 1989;5:372-378.

6. Hansen DW. Evaluating the eye with corneal topography. Contact Lens Spectrum 2003;18(8):27-32.

7. Maeda N, Klyce SD, Smolek MK, Thompson HW. Automated keratoconus screening with corneal topography analysis. Invest Ophthalmol Vis Sci 1994;35:2749-2757.

8. Rabinowitz YS, McDonnell PJ. Computer-assisted corneal topography in keratoconus. Refract Corneal Surg 1989;5:400-408.

9. Rabinowitz YS, Rasheed K. KISA\% index: a quantitative videokeratography algorithm embodying minimal topographic criteria for diagnosing keratoconus. J Cataract Refract Surg 1999;25:1327-1335. 
10. Rabitnowitz YS. Videokeratographic indices to aid in screening for keratoconus. J Refract Surg 1995;11:371-379.

11. Maeda N, Klyce SD, Smolek MK, Thompson HW. Automated keratoconus screening with corneal topography analysis. Invest Ophthalmol Vis Sci 1994 May;35(6):2749-2757.

12. Rabinowitz YS. Keratoconus. Surv Ophthalmol 1998;42(4):297-319.

13. Smadja D, Touboul D, Cohen A, Doveh E, Santhiago MR, Mello GR, Krueger RR, Colin J. Detection of subclinical keratoconus using an automated decision tree classification. Am J Ophthalmol 2013;156(2):237-246.

14. Arbelaez MC, Versaci F, Vestri G, Barboni P, Savini G. Use of a support vector machine for keratoconus and subclinical keratoconus detection by topographic and tomographic data. Ophthalmol 2012;119(11):2231-2238.

15. Alió JL, Piñero DP, Alesón A, Teus MA, Barraquer RI, Murta J, Maldonado MJ, Castro de Luna G, Gutiérrez R, Villa C, UcedaMontanes A. Keratoconus-integrated characterisation considering anterior corneal aberrations, internal astigmatism, and corneal biomechanics. J Cataract Refract Surg 2011;37(3):552-568.

16. Vega-Estrada A, Alió JL, Brenner LF, Javaloy J, Plaza Puche AB, Barraquer RI, Teus MA, Murta J, Henriques J, Uceda-Montanes A. Outcomes analysis of intracorneal ring segments for the treatment of keratoconus based on visual, refractive and aberrometric impairment. Am J Ophthalmol 2013;155(3):575-584.

17. Ortiz D, Piñero D, Shabayek MH, Arnalich-Montiel F, Alió JL. Corneal biomechanical properties in normal, post-laser in situ keratomileusis and keratoconic eyes. J Cataract Refract Surg 2007;33(8):1371-1375.

18. Alió JL, Shabayek MH. Corneal higher-order aberrations: a method to grade keratoconus. J Refract Surg 2006;22(6):539-545.

19. Tuft SJ, Moodaley LC, Gregory WM, Davison CR, Buckley RJ. Prognostic factors for the progression of keratoconus. Ophthalmol 1994;101(3):439-447.

20. Wagner H, Barr JT, Zadnik K. Collaborative longitudinal evaluation of keratoconus study: methods and findings to date. Cont Lens Anterior Eye 2007;30(4):223-232.

21. Amsler M. Keratocone classique et keratocone fruste, arguments unitaires. Oftalmologica 1946;111:96-101.

22. Piñero DP, Alió JL, Barraquer RI, Michael R. Corneal biomechanical changes after intracorneal ring segment implantation in keratoconus. Cornea 2012 May;31(5):491-499.

23. Saad A, Gatinel D. Topographic and tomographic properties of forme fruste keratoconus corneas. Invest Ophthalmol Vis Sci 2010 Nov;51(11):5546-5555.

24. Ambrósio R Jr, Belin MW. Imaging of the cornea: topography vs tomography. J Refract Surg 2010 Nov;26(11):847-849.

\section{GUIDELINES FOR THERAPEUTIC MANAGEMENT}

The primary aim of treatment for patients with keratoconus is visual restoration by remodeling the corneal geometry and arresting the progressive nature of the disease. In terms of visual restoration, correction with glasses is limited to a small group of patients whose corneal irregularity is not sufficiently pronounced to significantly compromise the patient's visual function. Meanwhile, patients who for whatever reasons are unable to tolerate contact lenses or are poorly inclined to use them must resort to a surgical alternative.

Until the last decade of the 20th century, the only surgical option for patients with keratoconus was keratoplastic procedures. However, nowadays there are numerous procedures that seek to stop progression of the disease and improve the patient's visual function.

Intracorneal ring segments (ICRS) implantation is a surgical procedure used as a treatment alternative in patients with keratoconus. ${ }^{1}$ Small devices made of a synthetic material are inserted deep within the corneal stroma in order to reshape corneal tissue, and thus improve the patient's visual function and tolerance to contact lenses. ${ }^{1}$

Corneal collagen cross-linking (CXL) is another surgical technique for the treatment of the ectatic disease. In this procedure, riboflavin and UV light are applied on the cornea to generate a photochemical reaction that induces the creation of links between collagen fibers, resulting in increased corneal tissue strength. As of today, it is the only technique which has been clinically shown to stop progression of the disease. ${ }^{2}$

In addition to these treatment options, it should be noted that there are patients with keratoconus who shall require surgical treatment. Excimer laser photorefractive keratectomy (PRK) is one of these surgical techniques that in the short-term improves visual function and quality in patients with keratoconus and mild to moderate refractive errors. ${ }^{3}$ Meanwhile, phakic lens implantation is a surgical technique which has been shown to be effective in patients with keratoconus and moderate to high refractive errors. ${ }^{4}$

In the following section, we describe the indications for the various surgical alternatives for treating keratoconus, based on the evidence partly developed by the cooperative research team which created the Iberia Keratoconus Database through the network collaboration of several research groups in Spain and Portugal and with the support of the Carlos III Health Institute [Cooperative Health Research Thematic Networks (RETICS) 'age-related eye disease, visual quality and quality-of-life', sub-project visual quality (RD07/0062), and RETICS 'prevention, early detection and treatment of the prevalent degenerative and chronic eye diseases', sub-program 'ocular structures and common pathologies' (RD12/0034/0007)] and on what is published in scientific literature. 


\subsection{Keratoconus Management in Patients with Contact Lenses}

It is worth noting and recalling the birth of modern contact lenses in the hands of Edwin Theodor Saemisch, who was the first to insert a contact lens into the eye for protective purposes. Following his footsteps, in the late 1880s, Adolph Eugen Fick, Eugene Kalt and August Müller worked independently on the first contact lenses with the idea of optically correcting the human eye. The first two, who were ophthalmologists, devised glass lenses to correct corneal abnormalities, i.e. for the optical correction of irregular corneal astigmatism which was very difficult to correct using standard procedures. The latter, who was a medical student, also produced a glass lens in order to correct his own -14.00 D myopia. ${ }^{5,6}$

These contact lenses were made of blown and polished glass and had a sclerocorneal design, covering much of the eye. They could only be worn for a short periods of time as they provoked signs and symptoms of corneal hypoxia. Nevertheless, the improvement they made to visual acuity was an encouraging reason to continue working in this area of ocular optical correction.

Over the years since then, an enormous number of lenses with special designs have been created using an extensive array of gas permeable polymers and hydrogels. Special emphasis has been paid to designing contact lenses for patients with keratoconus, as most professionals usually advise optical treatment of keratoconus with contact lenses before resorting to surgical methods. Contact lenses continue to be the mainstay of optical correction, by compensating higher-order corneal aberrations and improving visual acuity in patients for whom ophthalmic lens correction is no longer an adequate solution.

In addition, these advances in both the manufacture and design of contact lenses to ensure a more accurate fit to the type of cone have been supported by the development and creation of corneal topography and optical coherence tomography, making fitting in keratoconus safer and more effective.

Contact lenses are the main support treatment for keratoconus and one of the first treatments of choice in $90 \%$ of patients due to corneal surface irregularity. ${ }^{7-9}$ The choice of contact lens will be based on the same selection criteria for any contact lenses fitting, eventually using the contact lens that provides the greatest comfort and highest visual acuity possible. Fitting will also depend on the degree of ectatic disease progression, corneal stability and the ocular conditions present. We, currently, have several compensation options, given that there is no single contact lens design suitable for all cases of keratoconus. ${ }^{10}$

- Soft contact lenses

- Rigid gas permeable (RGP) lenses

- Hybrid lenses (rigid center and soft peripheral hydrophilic skirt)

- Scleral lenses

- Piggyback system (rigid lens on soft lens).

\subsubsection{Soft Contact Lenses}

Indicated in the early grades of the disease, when there is atypical topography and corrected visual acuity is normal or slightly diminished, that is, when keratoconus is mild with certain higher-order aberrations. When choosing this type of correction, it is normal to use toric soft lenses to compensate for the astigmatism always present in keratoconus.

Soft lenses provide acceptable optics and a comfortable fit in cases in which the cone is located near the line of sight and the apex of the cone is not too steep. To improve these results, special new hydrogels are currently being developed which include small optical zones, thicker central thicknesses and aspheric internal surfaces. In this area, there are also personalized wavefront-guided soft contact lenses which facilitate fitting in these special cases.

\subsubsection{Rigid Gas Permeable Lenses}

Used in cases in which patients have an irregular topography and more higher-order aberrations, i.e. when fitting of soft contact lenses is not possible because their flexibility does not sufficiently mask the irregular cornea. In these cases, RGP lenses are the most appropriate for optical compensation of keratoconus; they provide the eye with a perfect anterior surface free of aberrations, since all irregularities of the anterior corneal surface are masked and compensated by the tear film formed between the inner surface of the lens and the anterior surface of the corneal tissue.

Fitting these kinds of lenses requires a good lens/cornea fitting relationship and a good tear interchange to reduce the high sensitivity of patients and result in a successful fit. 
These lenses are generally required with small diameters, and are thus considered corneal lenses. As the diameter of the cone increases, so should the back optic zone diameter (BOZD), the back curve radius and the lens diameter, resulting in a better match between the sagitta (sag) of the cone and the sag of the back optic zone.

In cases where the optical zone is too large compared to the diameter of the cone, the sag of the contact lens will be greater than the sag of the cone and there will be clearance around the cone, causing bubbles to be formed in the tear film, which will affect visual function (Fig. 7).
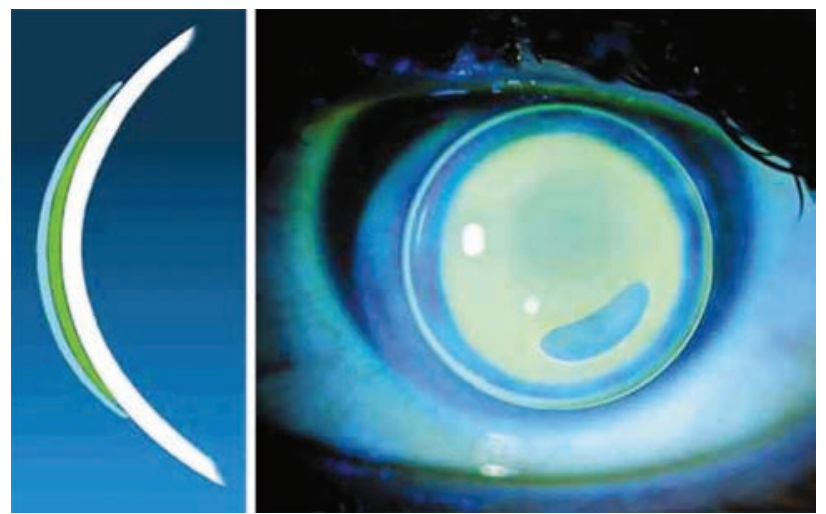

Fig. 7: Curved or closed fitting lens. Tears are trapped in the center of the lens, with poor interchange and formation of bubbles upon blinking ${ }^{17}$

If the optical zone of the lens is too small, the sag of the contact lens will be smaller than the sag of the cone, which is problematic for the lens causing an unstable, decenterd fit on the cornea (Fig. 8).
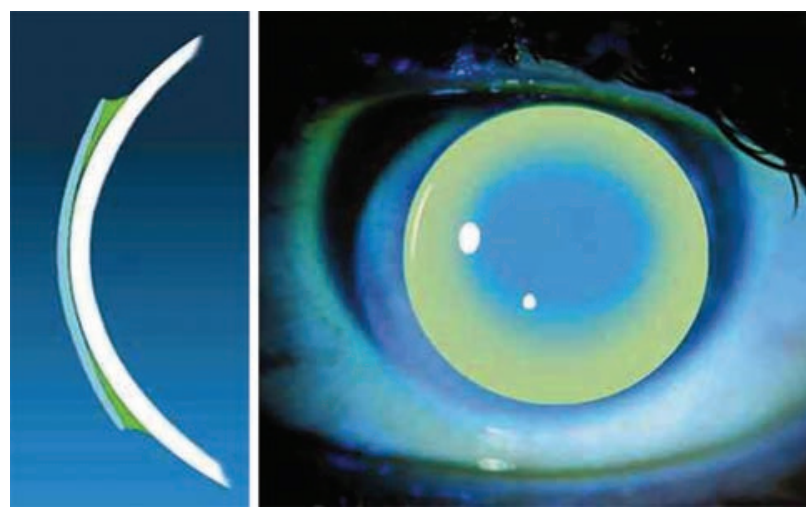

Fig. 8: Flat fitting lens. Rests too heavily in the center cone area and can lead to epithelial damage, apical scarring, limit tolerance and risk of greater progression ${ }^{17}$

Lastly, for a good fit, the peripheral zone of the lens needs to flatten more than the peripheral cornea and, in doing so, should have an axial edge lift with eccentricity values for keratoconic eyes ranging from 0.65 to over 1.0 in advanced cases (Fig. 9).
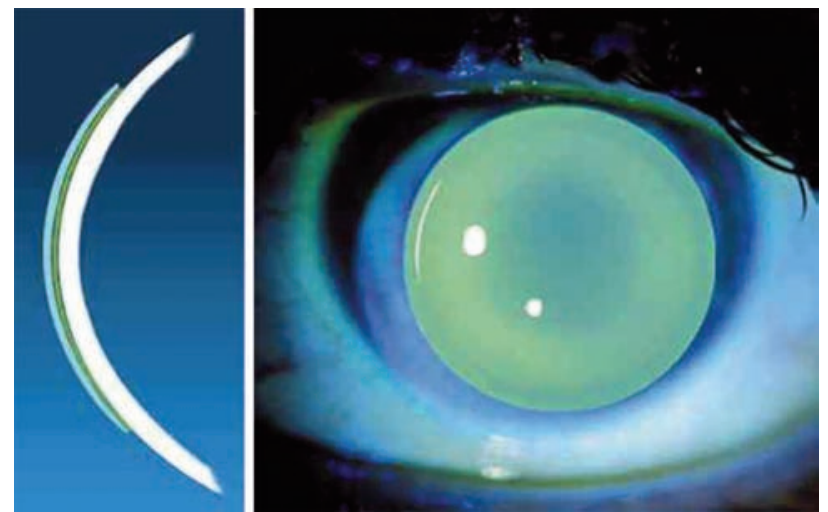

Fig. 9: Parallel fit. Good lens/cornea relationship resulting in apical clearance with minimal 'three-point touch', minimal central bearing and slight para-central touch ${ }^{17}$ 
In the first two situations, for patients tolerant to RPG lenses with less than perfect vision with soft toric lenses, there are no corneal alterations to justify conducting keratoplasty. However, we can resort to other alternatives gaining tolerance and comfort without sacrificing good visual acuity. There are three main alternatives:

\subsubsection{Hybrid Lenses}

Hybrid lenses consist of a combination of a gas permeable central zone and a peripheral hydrophilic skirt (Fig. 10). The advantages of this system are based on combining the properties of gas permeable rigid material—correction of irregular astigmatism with good visual acuity — and those of soft lenses-greater stability, comfort and tolerance. ${ }^{11}$ Good fitting of these contact lenses should meet the following requirements:

- Comfort and centration

- Movement of 0.25 to $0.50 \mathrm{~mm}$ (tested by looking upward and by blinking)

- Tear interchange and no blocking (observed using high molecular weight fluorescein)

- Good optical quality.

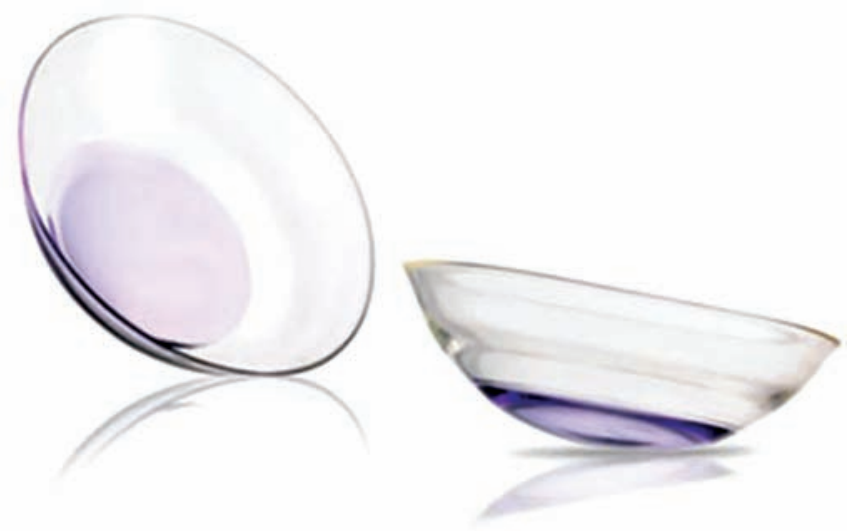

Fig. 10: Hybrid lens showing different materials in central zone and peripheral skirt

\subsubsection{Scleral Lenses}

Scleral lenses are designed to align with and rest on the scleral conjunctiva and to wrap around the cornea, without touching the cone (Fig. 11). The lens sag must be greater than the corneal slope in order to achieve this type of fitting relationship. In trapping tears beneath the lens, in addition to masking very large areas of corneal irregularity, these scleral lenses may have a therapeutic advantage for dry eyes. Tear exchange is accomplished through a pumping action of the upper eyelid over the contact lens surface, inducing flexure (positive pressure) of the center of the lens and negative pressure as the lens periphery draws tears under the lens. ${ }^{12}$

Three parts of the lens must be considered during fitting, and may be adjusted independently:

- The corneal zone, back optical zone radius (BOZR) and BOZD

- The mid peripheral zone over the corneal-scleral junction

- The scleral-conjunctival zone
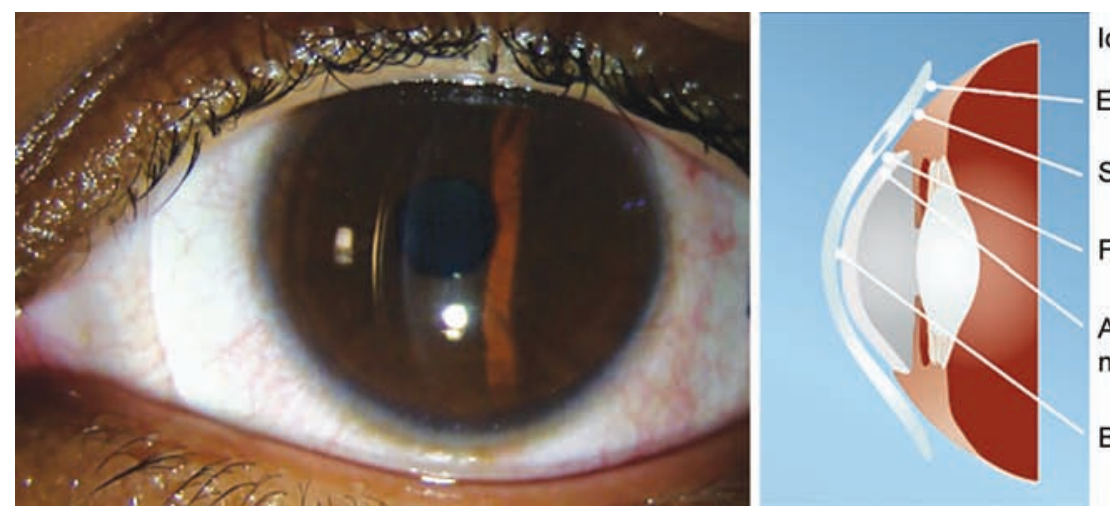

Ideal fit:

Edge zone flatter than scleral zone

Scleral zone slightly flatter than alignment

Fenestration above limbus in interpalpebral zone

Air bubble associated with fenestration may or may

not be presented

BOZR selected to minimize corneal contact

Fig. 11: Fitting of scleral contact lens ${ }^{16}$; ideal fit of scleral lens ${ }^{16}$ 
The first consideration to take into account when fitting this type of contact lens is the diameter, since each type of diameter can provide different benefits. Thus, lens diameter can be classified into different groups (Table 2).

Table 2: Classification of scleral lenses according to diameter

\begin{tabular}{ll}
\hline Lens diameter & Classification \\
\hline 12.9 to $13.5 \mathrm{~mm}$ & Corneoscleral \\
13.6 to $14.9 \mathrm{~mm}$ & Semi-scleral \\
15.0 to $18.0 \mathrm{~mm}$ & Mini scleral \\
18.1 to $24.0 \mathrm{~mm}$ & Scleral \\
\hline
\end{tabular}

- Larger diameter

- Larger tear reservoir

- Larger support area in the bearing zone

- Greater movement than smaller diameter lenses

- Greater decentration

- Smaller diameter

- Easy to use

- Some do not need fluid for insertion, so less bubble formation

- Less expensive

This type of contact lens usually shows little movement, with movement directly proportional to diameter, as mentioned above. Spontaneous movement after blinking is not common and vertical movement can cause discomfort and poor satisfaction. Lens movement is assessed by applying slight pressure using the push-up test; the lens should move slightly if well fit.

\subsubsection{Piggyback System}

Piggyback lenses consist of sandwiching a soft lens (a silicone hydrogel lens whenever possible) between an RPG lens and the cornea, thus improving mechanical tolerance and centration in some cases of keratoconus (Fig. 12).

Soft lenses are fitted slightly flat. The K reading is determined over the lens in the central anterior surface, and is then used to select the base curve of the RPG lens. This lens should have a reduced thickness and a diameter between 9 and $10 \mathrm{~mm}$ for maximum stability.

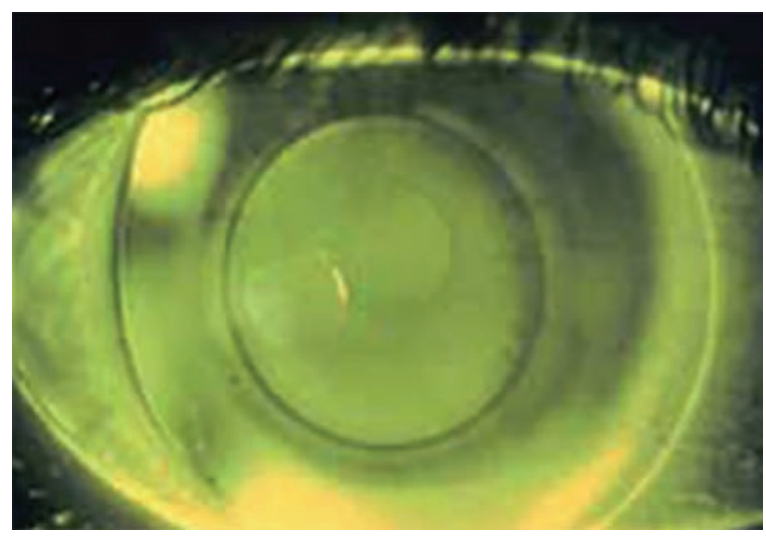

Fig. 12: Fluorescein pattern of RGP lens over silicone hydrogel lens ${ }^{17}$

Although there are obvious advantages of comfort, tolerance and correction in some patients, this system presents difficulties in obtaining an effective result, since maintaining a balance/stability relationship between both lenses is a real problem in fitting. While use of a positive-powered soft lens may help, the additional thickness entails a reduction in permeability.

In addition, excessive movement or the closed behavior of the rigid lens can cause alterations in the interface of the two lenses with the presence of bubbles or debris which decrease optical quality and alter corneal metabolism. As a result, areas of hypoxia/edema and formation of new vessels may be observed. When fitting is correct, limiting the number of hours the lenses are used may prevent complications; however, in keratoconus, dependence on correction with contact lenses leads to overuse. Abandoning use of the lenses is also common, because two different lenses and two cleaning systems are required and this leads to increased costs. ${ }^{13}$ 


\subsubsection{Fitting and Lens/Cornea Relationship}

Some diagnosed cases of keratoconus are related to anxious personality traits, ${ }^{14}$ in other words, they are difficult to manage clinically. Added to this are other individual aspects, such as narrow palpebral fissure or excessive palpebral tone, which would make the lens uncomfortable for the wearer. This discomfort is due to the instability of the lens and frequent movement resulting in epithelial erosion and fluctuating vision.

Despite a good fit in theory, over sensitivity to the rigid material is the cause of intolerance.

\subsubsection{Complications}

The choice of fitting parameters in keratoconus limits the chances for success compared to a healthy eye. These difficulties are increased when the extent of the cone affects two or three corneal quadrants, making it difficult to avoid areas of pressure and contact, thus causing visible corneal problems after hours of use. ${ }^{15}$

- Recurrent corneal erosion due to the absence of adequate tear film between the lens and the cornea. The aqueous part of the tear layer decreases and the mucin layer acts as an adherent between the lens and the cornea. It is usually asymptomatic, but there are cases where the amount of time lenses can be worn comfortably can decrease. In these cases, the optical zone diameter should be decreased, also correcting the new relationship between the base curve and the peripheral curves.

- Corneal spot characterized by a mesh-like scar located in the stroma of the cone apex and related to the clinical course of the disease.

- Corneal staining:

- Solution toxicity depends on the concentration of the solution used and can cause diffuse corneal staining in the area below the contact lens. The lens care system should be changed in this case.

- 3 and 9 O'clock staining is the result of a combination of many factors related to lens fit and the ocular surface.

How to treat this response:

$\Rightarrow$ Increase lens diameter

$\Rightarrow$ Reduce edge thickness

$\Rightarrow$ Ensure sufficient edge lift and lens centration

Proper lid hygiene and treatment of dry eyes is also extremely important to ensure adequate wearing times.

- Linear staining occurs when the posterior surface of the lens irritates the corneal surface due to excessive contact. Cleaning the back of the lens, smoothing out the junctions of the peripheral curves or trying an aspheric design are possible solutions to this problem.

- Apical staining occurs when the contact lens is too flat with apical touch and excessive movement (apical rotation).

- Dimple veiling is the impression made by air bubbles on the corneal surface. These bubbles are of no longterm importance physiologically, but may have associated symptoms of discomfort. They may interfere with vision, if present centrally. To resolve this condition, the area of clearance can be reduced in the following ways:

- Decrease amount of apical clearance (if bubbles are located over cone)

- Reduce BOZD (if bubbles are located around the cone)

- Reduce axial edge lift (if bubbles are located at the lens periphery).

\section{REFERENCES}

1. Meek KM, Hayes S. Corneal cross-linking—a review. Ophthalmic Physiol Opt 2013 Mar;33(2):78-93.

2. Piñero DP, Alió JL. Intracorneal ring segments in ectatic corneal disease—a review. Clin Experiment Ophthalmol 2010 Mar;38(2): 154-167.

3. Tamayo Fernandez GE, Serrano MG. Early clinical experience using custom excimer laser ablations to treat irregular astigmatism. J Cataract Refract Surg 2000 Oct;26(10):1442-1450.

4. Alió JL, Peña-Garcia P, Abdulla F, Zein G, Abumustafa S. Phakic intraocular lenses in keratoconus: a comparison between Artiflex and implantable collamer lens. JCRS (accepted for publication July 2013).

5. Pearson RM. Kalt, keratoconus, and the contact lens. Optom Vis Sci 1989 Sep;66(9):643-646.

6. Pearson RM, Efron N. Hundredth anniversary of August Müller's inaugural dissertation on contact lenses. Surv Ophthalmol 1989 Sep-Oct;34(2):133-141.

7. Rabinowitz YS, Garbus JJ, Garbus C, McDonnell PJ. Contact lens selection for keratoconus using a computer-assisted videophotokeratoscope. CLAO J 1991 Apr;17(2):88-93. 
8. Rosenthal P, Cotter JM. Clinical performance of a spline-based apical vaulting keratoconus corneal contact lens design. CLAO J 1995 Jan;21(1):42-46.

9. Yeung K, Eghbali F, Weissman BA. Clinical experience with piggyback contact lens systems on keratoconic eyes. J Am Optom Assoc 1995 Sep;66(9):539-543.

10. Garcia-Lledo M, Feinbaum C, Alió JL. Contact lens fitting in keratoconus. Compr Ophthalmol Update 2006 Mar-Apr;7(2):47-52.

11. Carracedo G, González-Méijome JM, Lopes-Ferreira D, Carballo J, Batres L. Clinical performance of a new hybrid contact lens for keratoconus. Eye Contact Lens 2014 Jan;40(1)2-6.

12. Schornack MM, Patel SV. Scleral lenses in the management of keratoconus. Eye Contact Lens 2010 Jan;36(1):39-44.

13. Tsubota K, Mashima SY, Murata H, Yamada M. A piggy-back contact lens for the correction of irregular astigmatism in keratoconus. Ophthalmol 1994 Jan;101(1):134-139.

14. Lema I, Diez-Feijoo E, Ruiz C, et al. Corrección del astigmatismo irregular con lente SoftPerm. Arch Soc Esp Oftalmol 1997;72: 587-592.

15. Edrington TB, Zadnik K, Barr JT, et al. (CLEK Study Group). Scarring and contact lens fit in keratoconus: results from the contact lens evaluation in keratoconus screening study. Invest Ophthalmol Vis Sci 1991;32(Suppl):738.

16. Luigina S. Correction of keratoconus with GP lenses. Craig W, Alisa S, editors. School of Optometry, University of Waterloo, Waterloo, Canada.

17. Juan A. Durán de la Colina. Complicaciones de las lentes de contacto. Madrid, Spain: Tecnimedia Editorial S.L.; 1998.

\section{CORNEAL COLLAGEN CROSS-LINKING}

\subsection{Introduction}

Cross-linking (CXL) is a term used in the biological sciences to describe the formation of chemical bridges following a chemical reaction between proteins and other molecules. These chemical bridges can be formed from chemical reactions initiated by heat, pressure or radiation in such a way that changes the physical properties of the material.

This phenomenon occurs naturally in the human body during the ageing process or in patients with diabetes mellitus where molecular changes occur in proteins and body tissues leading to the loss of elasticity and rigidness. The use of collagen CXL arose after observing the absence of corneal ectasia progression in patients with diabetes mellitus. ${ }^{1-5}$

This idea of generating stiffness or causing a loss of elasticity of corneal collagen fibers, i.e. induce corneal CXL was performed by a research group at the Dresden Technical University ${ }^{6}$ where using riboflavin (vitamin B2) and ultraviolet A (UVA) radiation they hoped to increase the formation of crossed links between the collagen fibers in the corneal stroma, producing a rigid effect capable of halting the progression of the ectasia.

Following along this line of thought, over the past decade this technique has been introduced into clinical practice to treat corneal ectatic disorders, such as keratoconus, pellucid marginal corneal degeneration and corneal ectasia after refractive surgery. So, patients diagnosed with corneal ectatic disorders now have the possibility of detaining the disease progression thus avoiding more complex and severe treatments such as corneal transplantation.

\subsection{Mechanisms of Action}

The basic principle of cross-linking is the use of a combination of a photosensitive substance $(0.1 \%$ riboflavin with or without $20 \%$ dextran) and its stimulation by type A ultraviolet (UVA) light.

Riboflavin is an effective photo-activator with a characteristic UV sensitivity because when it absorbs light it reaches a state of excitement that allows it to interact with molecular oxygen generating atomic oxygen (type II mechanism) or interacting directly on a formed substrate and the photo-oxidation of this with the consequent generation of intermediate radicals (type I mechanism) forming reactive oxygen species, such as superoxide anion, hydroxyl radical and hydrogen peroxide. The $20 \%$ dextran allows osmolar stabilization and maintenance of corneal thickness during the procedure.

After the application of UVA light, photopolymerization of the corneal stroma occurs due to the photo-oxidation and release of $\mathrm{O}_{2}$ and free radicals that generate the formation of new covalent links within the collagen fibers which permits corneal cross-linking. The reactive species can then, in principle, induce covalent cross-linking of many different molecules, including collagen, proteoglycan (extracellular matrix molecules which consist of a protein nucleus to which sulfated glycosaminoglycans are linked), DNA and RNA. Lysine is hypothesis as being responsible for the effect but the precise steps have not yet been determined as we have been unable to return to the grade prior to the formation of the new collagen bonds. 
Cross-linking has been shown to generate various effects in the cornea, such as increased stiffness, changes in biomechanical and bioelastic behavior of the tissue and different visual, refractive, topographic and aberrometric changes in the patient.

\subsection{Surgical Techniques-Protocols}

The concentration of riboflavin in the stroma is an extremely important requirement in order to obtain a good CXL effect on the corneal structure. This concentration in the stroma can be achieved in many ways with the main one being the standard protocol which has been modified to generate new methods.

- Standard 'Epithelium-off' protocol

As mentioned above, corneal CXL use dates back to 1997 but it did not begin to be used in a standardized fashion until 2007, following the standard protocol which has become known as the Dresden protocol. ${ }^{6}$ Following the application of topical anesthetic, the corneal epithelium (8-9 mm diameter) is removed. The corneal stroma is then saturated with an isotonic $0.1 \%$ riboflavin and $20 \%$ dextran solution, instilling one drop every 2 minutes for 30 minutes. After checking using the slit-lamp that complete stromal saturation has been achieved, it then undergoes UVA radiation at $5.4 \mathrm{~J} / \mathrm{cm}^{2}\left(3 \mathrm{~mW} / \mathrm{cm}^{2}\right)$ for 30 minutes. Finally, after this treatment, a therapeutic contact lens with topical corticosteroids, antibiotics and non-steroidal anti-inflammatory agents is fitted until regeneration of the epithelium. $^{7-9}$

\subsection{Modifications to the Standard Procedure}

\subsubsection{Reducing Postoperative Complications}

- Transepithelial 'Epi-on' protocol

The interconnections between epithelial cells constitute a major barrier to the penetration of riboflavin. Because of this, to ensure the effectiveness of the technique, the epithelium is removed but it is this removal that causes most of the CXL complications: pain, delays in epithelium regeneration, infection, haze, corneal melting, etc.

To avoid these complications, in recent years several research teams have tried to find alternate techniques that would enable the corneal epithelium to remain in intact without compromising riboflavin penetration.

- Altering epithelial permeability (benzalkonium chloride): With benzalkonium chloride, the separation between cells of the corneal epithelium is increased due to the rupture of cell binding and the partial loss of these cells. ${ }^{10,11}$ The first study without epithelial debridement was conducted by Wollensak et al in which benzalkonium chloride $0.005 \%$ was instilled into the eyes of rabbits and a slight biomechanical effect was observed. ${ }^{12}$ The Kissner team $^{2}$ tested various concentrations of benzalkonium chloride $0.1 \%$ in rabbits' eyes and observed good UV absorption and a good biomechanical effect. ${ }^{13}$

The problem with this procedure is that not all corneas not respond in the same way to these substances so, it is difficult to standardize the method.

- Mechanical modification (Daya disrupture): This is based on a circular instrument with a 9 mm diameter made up of 40 evenly-spaced fine points with which small pores are created in the epithelium and through which the riboflavin can directly reach the corneal stroma. ${ }^{14}$

- Direct application: Daxer et al proposed creating a corneal pocket through which riboflavin is instilled into the stroma. ${ }^{15}$ This idea has also been used by creating tunnels during intracorneal segment surgery and the tunnel is then flooded with riboflavin. ${ }^{16-18}$

Another technique, that is, currently under investigation is instilling riboflavin through an array of needles inserted in the anterior stroma. ${ }^{19}$

- Iontophoresis: This is a non-invasive technique in which the mobility of ions is induced by a low voltage electric field to accelerate penetration and increase riboflavin concentrations, thereby reducing treatment times and increasing efficiency. ${ }^{20,21}$

\subsubsection{Reducing Treatment Times}

Another line of investigation concerning optimization of the technique is reducing treatment times without compromising performance. The use of higher UVA radiation intensities for example is being considered. Thus, 
the standard procedure, as discussed above, would be carried out with UVA radiation at $5.4 \mathrm{~J} / \mathrm{cm}^{2}\left(3 \mathrm{~mW} / \mathrm{cm}^{2}\right)$ for 30 minutes in a 8 to $9 \mathrm{~mm}$ area.

However, what is noted is that this same level of radiation exposure can be achieved using a higher intensity for a shorter time. Studies conducted in pig corneas have shown that increasing illumination intensity to $10 \mathrm{~mW} / \mathrm{cm}^{2}$ meant that exposure time could be reduced to 9 minutes, obtaining results of increased corneal rigidity. ${ }^{32}$ These procedures of increased illumination intensities have not yet been used in vivo.

Scientific evidence on what is known as oxygen-dependent cross-linking procedures raises some concerns about the effectiveness of treatment methods that aim to decrease exposure time by increasing the intensity of the radiation energy. By increasing the energy intensity, oxygen is consumed more quickly so that the cross-linking effect cannot be produced in an efficient manner. ${ }^{33}$

\subsubsection{Facilitating Treatment in Cases of very Thin Corneas}

As discussed in the following section, patient selection involves some requisites such as corneas with a pachymetry over $400 \mu \mathrm{m}$ in order to avoid damaging the endothelial cells by UVA radiation. ${ }^{9,25,26}$ As many patients with keratoconus have a corneal thickness of less than $400 \mu \mathrm{m}$, various CXL methods have been developed to treat this patient population with varying degrees of success.

- Increasing corneal thickness to $400 \mu \mathrm{m}$ by applying a hypo-osmolar riboflavin solution, thereby increasing the endothelium toxicity threshold. ${ }^{34}$ It was possible to increase the thickness of the posterior stroma facilitating treatment in cases of corneas with a minimum thickness $320 \mu \mathrm{m}$, with positive results. ${ }^{35,36}$ When hypo-osmolar riboflavin solution for topical application was not available, the idea arose of applying UVA radiation according to corneal thickness without exceeding endothelial cell toxicity threshold $\left(0.63 \mathrm{~J} / \mathrm{cm}^{2}\right)$.

- Increasing the riboflavin concentration to $0.2 \%$ leads to greater UVA light absorption in the anterior stroma and therefore less UVA radiation exposure for endothelial cells.

- Customized epithelial debridement technique. This is based on modifying the treatment to excise the epithelium only in regions with corneal thickness exceeding $400 \mu \mathrm{m} .{ }^{37}$ If the riboflavin does not penetrate sufficiently beneath the epithelium, this treatment effect may be insufficient. ${ }^{38}$

- Using low riboflavin doses that are sufficient in the anterior stroma but insufficient to reach the endothelium. The rationale is that the endothelial cell toxicity threshold is much higher without riboflavin so, the endothelium would be better protected. This requires a short preliminary irradiation time with a high intensity radiation energy to maintain a short diffusion time. Currently, there is no clinical experience with this technique.

\subsection{Patient Selection: Indications and Contraindications}

Currently, the indications for cross-linking include various types of ectasia, such as keratoconus, pellucid marginal degeneration and postoperative refractive ectasia. There is still no pattern that would allow us to predict how each keratoconus will react after cross-linking therapy. We do, however, know that the most effective time to perform this technique is in patients with progressive keratoconus who still have good corrected visual acuity (RETICS classification grades II and III). ${ }^{30,31}$

To perform this treatment, the following principles must be taken into account:

- Indications

- Clinical manifestations of progressive kereratoconus ${ }^{22,23}$

- Age: under 35 years $^{24}$

- Visual acuity less than $0.8(20 / 25 ; \text { LogMAR } 0.1)^{24}$

- Pachymetry over 400 microns ${ }^{25,26}$

- Keratometry readings less than 58 D. $^{22,24}$

- Contraindications

- Pregnancy and breastfeeding ${ }^{26,27}$

- Age: can be a risk factor causing visual loss, but for the moment no limit has been established ${ }^{29}$

- Visual acuity: As a visual loss risk factor, CVA $\geq 0.8(20 / 25 ; \text { LogMAR } 0.1)^{24}$

- Cornea with central opacity ${ }^{28}$

- Serious dry eye syndrome. ${ }^{9}$ 


\subsection{Effect of Cross-Linking on Cornea}

- Biomechanical: It has been scientifically proven that CXL significantly increases corneal rigidity immediately after treatment, with a $71.9 \%$ increase of Young's modulus in pig corneas and a $328.9 \%$ increase in human corneas. ${ }^{39}$ This was corroborated in a study using rabbit eyes which also confirmed that the effect of stiffness persisted 8 months post-treatment. ${ }^{40}$

- Cell structures: As well as the effect of biomechanical rigidity as explained above, the reaction produced in the corneal cell populations has also been a subject thoroughly investigated using histological and confocal microscopy methods in vivo.

- Epithelial cells: With the standard procedure after its removal, the epithelium is fully regenerated within 3 to 4 days post-treatment by peripheral epithelial cells. With confocal microscopy in vivo, the thickness of the epithelium was seen to resemble preoperative values 1 month post CXL. ${ }^{41}$

- Furthermore, limbal stem cells were not damaged during CXL as they were protected by the epithelial cells. ${ }^{42}$

- Keratocytes: During the stromal healing process, it was possible to observe using confocal microscopy in vivo an increase in the density of the extracellular matrix combined with the presence of keratocytes nuclei 3 to 6 months after CXL. More new collagen fibers with nuclear activation of keratocytes was also detected after treatment. ${ }^{42}$

- Endothelial cells: Some animal experimental studies aimed to evaluate the cytotoxic effects on the corneal endothelium following the combination of riboflavin with UVA light. ${ }^{45}$ It was observed that a high energy dose $\left(4 \mathrm{~mW} / \mathrm{cm}^{2}\right.$ radiation on epithelium and $0.5 \mathrm{~mW} / \mathrm{cm}^{2}$ on endothelium) causes significant necrosis of endothelial cells. However, there are few cases of endothelial damage post-treatment. To avoid endothelial damage in corneas with a thickness of $400 \mu \mathrm{m}$, a radiation of this layer should be $0.18 \mathrm{~mW} / \mathrm{cm}^{2}$.

- Nerve cells: The use of CXL causes the subepithelial nerve plexus to disappear. ${ }^{43} \mathrm{~A}$ significant alteration in corneal nerve morphology was also observed after CXL but this was regenerated 7 days later. ${ }^{44}$

\subsection{Others uses of Cross-Linking}

Today, corneal collagen cross-linking is one of the main areas of research interest in ophthalmology. There is an increasing number of new possibilities of how this technique may be used to treat various diseases.

- Other types of ectasia: Over the past few years, various authors have reported the successful use of CXL to treat other forms of ectasia, such as pellucid marginal degeneration, ${ }^{48}$ iatrogenic ectasia ${ }^{47}$ or radical keratotomy. ${ }^{46}$ In all cases, there was partial regression of ectasia after CXL treatment.

- Stabilization of corneal procedures: The combination of CXL with other corneal procedures is still in its early grades, so much remains to be discovered. With the idea of stabilizing the shape of the altered cornea, it has been used in intrastromal corneal rings implants, ${ }^{49}$ after LASIK or PRK surgery, ${ }^{50,51}$ photoreactive keratectomy, ${ }^{52}$ orthokeratology $\mathrm{y}^{54}$ and thermokeratoplasty (Keraflex). ${ }^{53}$

- Infectious keratitis: The treatment of microbial keratitis using CXL has recently raised interest among the scientific community. To date, it has been clinically proven that CXL can prove beneficial in cases of resistant pathogens, such as Streptococcus pneumoniae and Gram-negative Escherichia coli. ${ }^{55,56}$ In all the published studies, there was rapid pain relief and acceleration of reepithelialization after CXL. Needless to say these cases should be treated with caution as there are risks of toxicity. We also need to bear in mind that not all pathogens respond positively to CXL treatment. The herpes simplex virus, for example, is stimulated by UV light aggravating the infection and may lead to corneal perforation. ${ }^{57}$

- Corneal edema: This commenced with a study by Wollensak et al ${ }^{58}$ in which CXL-treated and untreated porcine corneas were compared inside a moist chamber. They observed that the CXL-treated corneas swell less than the untreated corneas. This finding has led on to various investigations regarding CXL as a therapeutic option for conditions involving corneal edema.

\section{REFERENCES}

1. Malik NS, Moss SJ, Ahmed N, Furth AJ, Wall RS, Meek KM, et al. Ageing of the human corneal stroma: structural and biochemical changes. Biochim Biophys Acta 1992 Mar 20;1138(3):222-228. 
2. Sady C, Khosrof S, Nagaraj R. Advanced Maillard reaction and cross-linking of corneal collagen in diabetes. Biochem Biophys Res Commun 1995 Sep 25;214(3):793-797.

3. Bailey AJ, Paul RG, Knott L. Mechanisms of maturation and ageing of collagen. Mech Ageing Dev 1998 Dec 1;106(1-2):1-56.

4. Spoerl E, Wollensak G, Seiler T. Increased resistance of cross-linked cornea against enzymatic digestion. Curr Eye Res 2004 Jul; 29(1):35-40.

5. Kuo IC, Broman A, Pirouzmanesh A, Melia M. Is there an association between diabetes and keratoconus? Ophthalmol 2006 Feb; 113(2):184-190

6. Seiler T, Spörl E, Huhle M, Kamouna A. Conservative therapy of keratoconus by enhancement of collagen cross-links. Association for Research in Vision and Ophthalmology 1996 annual meeting. Fort Lauderdale, Florida, April 21-26, 1996. Abstracts. Invest Ophthalmol Vis Sci 1996 Feb 15;37(3):S1-1154.

7. Sporl E, Schreiber J, Hellmund K, Seiler T, Knuschke P. Studies on the stabilisation of the cornea in rabbits (in German). Ophthalmol 2000 Mar;97(3):203-206.

8. Hayes S, O'Brart DP, Lamdin LS, Doutch J, Samaras K, Marshall J, Meek KM. Effect of complete epithelial debridement before riboflavin-ultraviolet-a corneal collagen cross-linking therapy. J Cataract Refract Surg 2008 Apr;34(4):657-661.

9. Spoerl E, Mrochen M, Sliney D, Trokel S, Seiler T. Safety of UVA-riboflavin cross-linking of the cornea. Cornea 2007 Mar;26(4): 385-389.

10. Boxer Wachler BS. Corneal collagen cross-linking with riboflavin. Cataract Refract Surg Today 2005;1:73-74.

11. Pinelli R. Corneal cross-linking with riboflavin: entering a new era in ophthalmology. Ophthalmology Times Europe 2006;2: 36-38.

12. Wollensak G, Iomdina E. Biomechanical and histological changes after corneal cross-linking with and without epithelial debridement. J Cataract Refract Surg 2009 Mar;35(3):540-546.

13. Kissner A, Spoerl E, Jung R, Spekl K, Pillunat LE, Raiskup F. Pharmacological modification of the epithelial permeability by benzalkonium chloride in UVA/Riboflavin corneal collagen cross-linking. Curr Eye Res 2010 Aug;35(8):715-721.

14. Cummings A, Daya SM, Kanellopoulos AJ, et al. The future of corneal collagen cross-linking. Cataract Refract Surg Today Europe 2011. p. 36-58.

15. Daxer A, Mahmoud HA, Venkateswaran RS. Corneal cross-linking and visual rehabilitation in keratoconus in one session without epithelial debridement: new technique. Cornea 2010 Oct;29(10):1176-1179.

16. Coskunseven E, Jankov MR 2nd, Hafezi F, Atun S, Arslan E, Kymionis GD. Effect of treatment sequence in combined intrastromal corneal rings and corneal collagen cross-linking for keratoconus. J Cataract Refract Surg 2009 Dec;35(12):2084-2091.

17. Ertan A, Karacal H, Kamburoglu G. Refractive and topographic results of transepithelial cross-linking treatment in eyes with intacs. Cornea 2009 Aug;28(7):719-723.

18. Kamburoglu G, Ertan A. Intacs implantation with sequential collagen cross-linking treatment in postoperative LASIK ectasia. J Refract Surg 2008 Sep;24(7):S726-729.

19. Daugimont L1, Baron N, Vandermeulen G, Pavselj N, Miklavcic D, Jullien MC, Cabodevila G, Mir LM, Préat V. Hollow microneedle arrays for intradermal drug delivery and DNA electroporation. J Membr Biol 2010 Jul;236(1):117-125.

20. Iontophoresis cuts riboflavin treatment time for corneal cross-linking. Euro Times. India, 2011.

21. Vinciguerra R, Spoerl E, Romano MR, et al. Comparative stress-strain measurements of human corneas after transepithelial UVinduced cross-linking: impregnation with iontophoresis, different riboflavin solutions and irradiance power. Invest Ophthalmol Vis Sci 2012;53 (E-abstract \#1518).

22. Meek KM, Hayes S. Corneal cross-linking_a review. Ophthalmic Physiol Opt 2013 Mar;33(2):78-93.

23. Raiskup F, Spoerl E. Corneal cross-linking with riboflavin and ultraviolet A. Part II. Clinical indications and results. Ocul Surf 2013 Apr;11(2):93-108.

24. Koller T, Mrochen M, Seiler T. Complication and failure rates after corneal cross-linking. J Cataract Refract Surg 2009 Aug;35(8): 1358-1362.

25. Hafezi F, Mrochen M, Iseli H, Seiler T. Collagen cross-linking with ultraviolet. A and hypo-osmolar riboflavin solution in thin corneas. J Cataract Refract Surg 2009 Apr;35(4):621-624.

26. Raiskup F, Spoerl E. Corneal cross-linking with riboflavin and ultraviolet A. Part II. Clinical indications and results. Ocul Surf 2013 Apr;11(2):93-108.

27. Hafezi F, Iseli HP. Pregnancy-related exacerbation of iatrogenic keratectasia despite corneal collagen cross-linking. J Cataract Refract Surg 2008 Jul;34(7):1219-1221.

28. Abad J, Panesso J. Corneal collagen cross-linking induced by UVA and riboflavin (CXL). Techniques in Ophthalmol 2008;6:8-12.

29. NICE guidance on photochemical corneal collagen cross-linkage using riboflavin and ultraviolet A.

30. Alió JL, Piñero DP, Alesón A, Teus MA, Barraquer RI, Murta J, Maldonado MJ, Castro de Luna G, Gutierrez R, Villa C, et al. Keratoconus-integrated characterisation considering anterior corneal aberrations, internal astigmatism and corneal biomechanics. J Catarct Refract Surg 2011;37(3):552-568.

31. Vega-Estrada A, Alió JL, Brenner LF, Javaloy J, Plaza Puche AB, Barraquer RI, Teus MA, Murta J, Henriques J, Uceda-Montanes A. Outcomes analysis of intracorneal ring segments for the treatment of keratoconus based on visual, refractive and aberrometric impairment. Am J Ophthalmol 2013;155(3):575-584.

32. Schumacher S, Oeftiger L, Mrochen M. Equivalence of biomechanical changes induced by rapid and standard corneal crosslinking, using riboflavin and ultraviolet radiation. Invest Ophthalmol Vis Sci 2011 Nov 25;52(12):9048-9052. 
33. Richoz O, Hammer A, Tabibian D, Gatzioufas Z, Hafezi F. The biomechanical effect of corneal collagen cross-linking (CXL) with riboflavin and UV-A is oxygen dependent. Transl Vis Sci Technol 2013 Nov;2(7):6.

34. Hafezi F, Mrochen M, Iseli HP, Seiler T. Collagen cross-linking with ultraviolet-A and hypo-osmolar riboflavin solution in thin corneas. J Cataract Refract Surg 2009 Apr;35(4):621-624.

35. Hafezi F. Limitation of collagen cross-linking with hypo-osmolar riboflavin solution: failure in an extremely thin cornea. Cornea 2011 Aug;30(8):917-919.

36. Raiskup F, Spoerl E. Corneal cross-linking with hypo-osmolar riboflavin solution in thin keratoconic corneas. Am J Ophthalmol 2011 Jul;152(1):28-32.e1.

37. Kymionis GD, Diakonis VF, Coskunseven E, Jankov M, Yoo SH, Pallikaris IG. Customised pachymetric guided epithelial debridement for corneal collagen cross-linking. BMC Ophthalmol 2009 Aug;9:10.

38. Kaya V, Utine CA, Yilmaz OF. Efficacy of corneal collagen cross-linking using a custom epithelial debridement technique in thin corneas: a confocal microscopy study. J Refract Surg 2011 Jun;27(6):444-450.

39. Wollensak G1, Spoerl E, Seiler T. Stress-strain measurements of human and porcine corneas after riboflavin-ultraviolet- A-induced cross-linking. J Cataract Refract Surg 2003 Sep;29(9):1780-1785.

40. Wollensak G, Iomdina E. Long-term biomechanical properties of rabbit cornea after photodynamic collagen cross-linking. Acta Ophthalmol 2009 Feb;87(1):48-51.

41. Mazzotta C, Caporossi T, Denaro R, Bovone C, Sparano C, Paradiso A, Baiocchi S, Caporossi A. Morphological and functional correlations in riboflavin UV A corneal collagen cross-linking for keratoconus. Acta Ophthalmol 2012 May;90(3):259-265.

42. Wollensak G, Mazzotta C, Kalinski T, Sel S. Limbal and conjunctival epithelium after corneal cross-linking using riboflavin and UVA. Cornea 2011 Dec;30(12):1448-1454.

43. Kymionis GD, Diakonis VF, Kalyvianaki M, Portaliou D, Siganos C, Kozobolis VP, Pallikaris AI. One-year follow-up of corneal confocal microscopy after corneal cross-linking in patients with post-laser in situ keratosmileusis ectasia and keratoconus. Am J Ophthalmol 2009 May;147(5):774-778.e1.

44. Xia Y, Chai X, Zhou C, Ren Q. Corneal nerve morphology and sensitivity changes after ultraviolet A/riboflavin treatment. Exp Eye Res 2011 Oct;93(4):541-547.

45. Wollensak G, Spoerl E, Wilsch M, Seiler T. Endothelial cell damage after riboflavin-ultra-violet-A-treatment in the rabbit. J Cataract Refract Surg 2003 Sep;29(9):1786-1790.

46. Mazzotta C, Baiocchi S, Denaro R, Tosi GM, Caporossi T. Corneal collagen cross-linking to stop corneal ectasia exacerbated by radial keratotomy. Cornea $2011 \mathrm{Feb} ; 30(2): 225-228$.

47. Hafezi F, Kanellopoulos J, Wiltfang R, Seiler T. Corneal collagen cross-linking with riboflavin and ultraviolet A to treat induced keratectasia after laser in situ keratomileusis. J Cataract Refract Surg 2007 Dec;33(12):2035-2040.

48. Spadea L. Corneal collagen cross-linking with riboflavin and UVA irradiation in pellucid marginal degeneration. J Refract Surg 2010 May;26(5):375-377.

49. Bedi R, Touboul D, Pinsard L, Colin J. Refractive and topographic stability of intacs in eyes with progressive keratoconus: fiveyear follow-up. J Refract Surg 2012 Jun;28(6):392-396.

50. Celik HU, Alagöz N, Yildirim Y, Agca A, Marshall J, Demirok A, Yilmaz OF. Accelerated corneal cross-linking concurrent with laser in situ keratomileusis. J Cataract Refract Surg 2012 Aug;38(8):1424-1431.

51. Kanellopoulos AJ, Binder PS. Collagen cross-linking (CCL) with sequential topography-guided PRK: a temporizing alternative for keratoconus to penetrating keratoplasty. Cornea 2007 Aug;26(7):891-895.

52. Kymionis GD, Portaliou DM, Kounis GA, Limnopoulou AN, Kontadakis GA, Grentzelos MA. Simultaneous topography-guided photorefractive keratectomy followed by corneal collagen cross-linking for keratoconus. Am J Ophthalmol 2011 Nov;152(5): 748-755.

53. Vega-Estrada A1, Alió JL, Plaza Puche AB, Marshall J. Outcomes of a new microwave procedure followed by accelerated crosslinking for the treatment of keratoconus: a pilot study. J Refract Surg 2012 Nov;28(11):787-792.

54. Calossi A, Romano F, Ferraioli G, Romano V. Orthokeratology and riboflavin-UVA corneal collagen cross-linking in keratoconus. J Emmetropia 2010;1:126-131.

55. Moren H, Malmsjo M, Mortensen J, Ohrström A. Riboflavin and ultraviölet a collagen cross-linking of the cornea for the treatment of keratitis. Cornea 2010 Jan;29(1):102-104.

56. Micelli Ferrari T, Leozappa M, Lorusso M, Epifani E. Micelli Ferrari L. Escherichia coli keratitis treated with ultraviolet A/ riboflavin corneal cross-linking: a case report. Eur J Ophthalmol 2009 Mar;19(2):295-297.

57. Kymionis GD, Portaliou DM. Corneal collagen cross-linking and herpetic keratitis. J Cataract Refract Surg 2013 Aug;39(8):1281.

58. Wollensak G, Aurich H, Pham D, Wirbelauer C. Hydration behaviour of porcine cornea cross-linked with riboflavin and ultraviolet A. J Cataract Refract Surg 2007 Mar;33(3):516-521.

\section{INDICATIONS OF INTRACORNEAL RING SEGMENTS}

Along with collagen cross-linking and thermoplastic techniques, the use of intracorneal ring segments (ICRS) in patients with keratoconus ${ }^{1-3}$ is one of the so-called 'corneoplastic' techniques that allow surgeons to reshape the cornea for therapeutic and refractive purposes (Fig. 13). Use of this technique is relatively recent, as it was introduced in 2000 by Colin et al. ${ }^{4}$ 


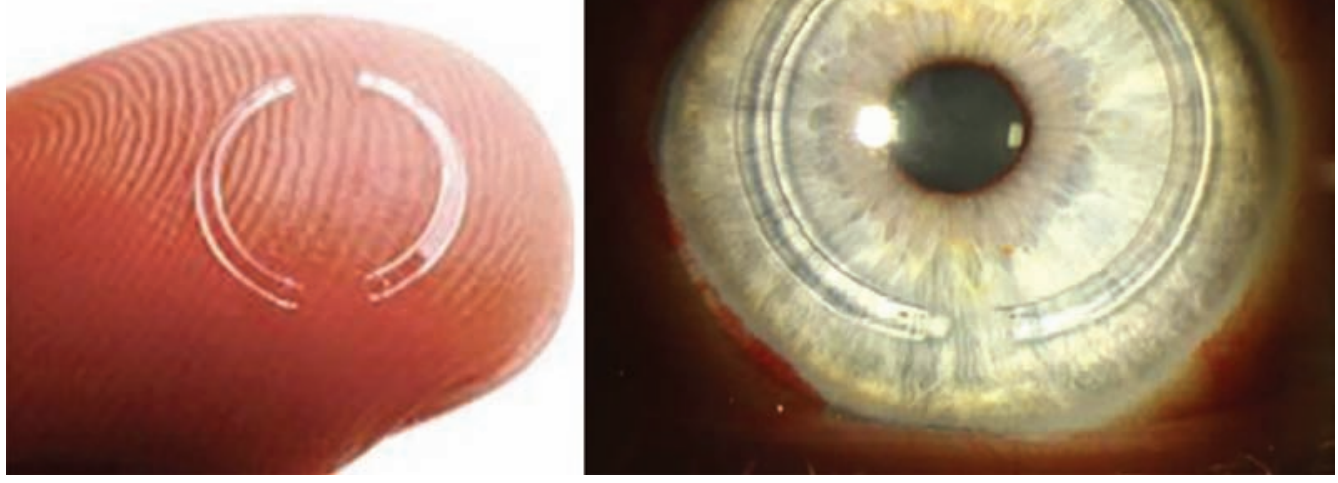

Fig. 13: Intracorneal segments

Intracorneal segments were initially designed for merely refractive purposes for patients not affected with keratoconus; however, this technique is now primarily used to remodel corneal shape in eyes with corneal ectasia. ${ }^{14-7}$ This reshaping can result in direct improvement by enhancing patients' visual acuity or in indirect improvement by facilitating contact lens fitting. Although contact lenses are a good option in the early grades of keratoconus because of their ability to reshape the corneal surface, they can be quite ineffective in advanced grades. This is due to the presence of very pronounced cones that make it impossible to attain centration without rotation (which is very important in these patients, since nearly all have to wear toric lenses).

\subsection{Types of Intracorneal Segments}

There are currently four main types of intracorneal segments:

1. Keraring

2. Intacs

3. Ferrara

4. Myoring

Keraring (MEDIPHACOS ${ }^{\circledR}$, Ophthalmic Professionals) and Ferrara rings are ring segments made of polymethyl methacrylate (PMMA). These segments are manufactured with different arc lengths $\left(90,120,160,210\right.$ and $\left.340^{\circ}\right)$, have a triangular cross-section, thicknesses ranging from 150 to $350 \mu \mathrm{m}$ and a variable optical zone ranging between 5 and $6 \mathrm{~mm}$. This allows for treatment to be customized depending on the needs in each case. Segments with shorter arc lengths are intended to reduce astigmatism, while longer arc lengths are effective in reducing keratometry. Segments can be implanted manually or using a femtosecond laser. A search of scientific literature reveals that implanting Keraring segments is effective in most cases and has a low rate of complications. Patients also report a high degree of satisfaction following surgery.

Intacs (AJL Ophthalmic ${ }^{\circledR}$ ) are semi-circular PMMA segments, each with an arc diameter of $150^{\circ}$ and a hexagonal cross-section. The segments have an external diameter of $8.10 \mathrm{~mm}$, an internal diameter of $6.77 \mathrm{~mm}$ and a total thickness ranging from 200 to $450 \mu \mathrm{m}$. There is another design for Intacs segments, called Intacs SK, which has an internal diameter of $6 \mathrm{~mm}$ and an oval cross-section and comes in two thicknesses, 400 and $450 \mu \mathrm{m}$. Results reported with this type of segment have also shown the segments to be effective; nevertheless, the reduction in the spherical equivalent is smaller compared to segments which are implanted in optical zones with a smaller diameter.

Ferrara (AJL Ophthalmic ${ }^{\circledR}$ ) segments are also made of PMMA and have a $5 \mathrm{~mm}$ diameter, an arc length ranging from 120, 160 to $210^{\circ}$ and a thickness between 150 and $300 \mu \mathrm{m}$. Like Keraring segments, they have a triangular cross-section in order to reduce glare and halos.

Lastly, we have Myoring rings (DIOPTEX ${ }^{\circledR}$ ), which are $360^{\circ}$ segments, that is, full-ring implants to be implanted into a corneal stromal pocket. They have a greater capacity to flatten and reduce the spherical equivalent than segments, but do not usually significantly reduce astigmatism and therefore their use is limited to cases in which patients have a high spherical error and low astigmatism.

\subsection{Surgical Procedure: Indication and Selection of ICRS Implants in Corneal Ectatic Disease}

Intracorneal ring segments are implanted by dissecting tunnels in the corneal stroma in one of two ways, either manually or using a femtosecond laser. With the manual technique, the surgeon marks the geometric center of the 
cornea or of the pupil depending on the criteria being followed. Then an incision is made at 70 to $80 \%$ of the corneal thickness. Afterwards, a suction ring is placed on the corneal limbus to ensure fixation of the eyeball during the rest of the procedure. Once the suction ring is in place, the surgeon creates a tunnel in the corneal stroma on each side of the incision using semi-circular dissectors that allow tissue to be dissected clockwise and anticlockwise. The segments are then inserted into the tunnel in the corneal stroma. The surgeon can opt to suture the incision, particularly in cases where there is a clear risk of complications.

The following procedure is used to create the tunnels using a femtosecond laser. As with the manual technique, the cornea is marked at the geometric center and a disposable suction ring is placed on the cornea centered on this point. Then the cone is positioned so as to flatten the cornea and ensure correct distance between the laser head and the focal point on the cornea. The tunnels are created in the corneal stroma at a depth of approximately 70 to $80 \%$ of corneal thickness in the area where dissection will be performed. Lastly, the laser makes a vertical incision through which the segments will be inserted in the thickness of the tunnel.

In theory, the femtosecond laser produces a more precise and controlled stromal dissection compared with manual dissection. However, if we are talking about visual and refractive parameters, most studies that have been conducted concur that both techniques produce similar results in cases of ICRS implantation to treat keratoconus. This has been mentioned by several authors reporting the safety and efficacy of femtosecond laser treatment making the process faster, easier (especially for inexperienced surgeons) and more comfortable for the patient. ${ }^{7,13-15}$ Apart from the safety and efficacy differences between both techniques, our research team found that intrastromal segment implantation using femtosecond laser is a method that produces a greater reduction in corneal high order aberrations in eyes with coma aberration $>3.0 \mu \mathrm{m} .{ }^{7,13}$

Regardless of the technique used to make the tunnels in the corneal stroma, the number, thickness and arc length of the segments are determined based on the manufacturer's nomogram. Likewise, rings are chosen from the nomogram taking into account the refractive error and the topographic map of the disease (Figs 14 and 15). It should also be noted that the incision guiding implantation of the segments in the tunnel is located on the axis of the steepest meridian of the corneal topography. In this case, for the Keraring (MEDIPHACOS ${ }^{\circledR}$, Ophthalmic Professionals) implant, three types of nomogram (A, B and C) (Figs 16 to 18) are used based on the type of corneal asymmetry (in other words, depending on the area in which irregularity is found relative to the reference meridian) (Figs 15 and 17), on keratometric values and on corrected visual acuity (CVA).

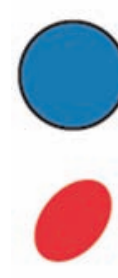

This blue circle represents the axial keratometric color map This image represents the steep area expressed In red colors on the corneal topography axial color map

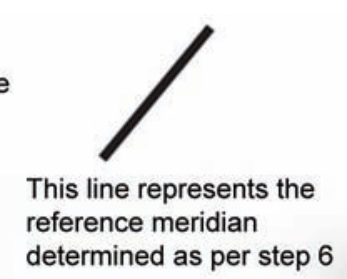

determined as per step 6

Fig. 14: Color coding

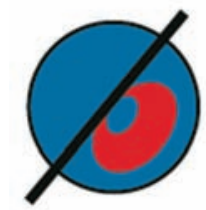

Type 1

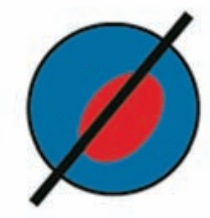

Type 2

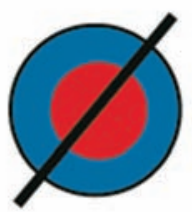

Type 3

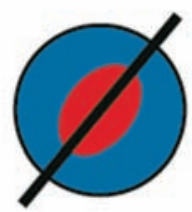

Type 4

Fig. 15: Corneal asymmetry classification according to the area where the corneal irregularity is found relative to the reference meridian

The corneal asymmetry type is determined by studying the distribution of corneal irregularity (red) relative to the reference meridian. Accordingly, each case is classified according to Figures 15 and 17.

Type 1: Hundred percent of the steep area is located on one side of the reference meridian.

Type 2: The distribution of the steep area is approximately $20 / 80 \%$.

Type 3: The distribution of the steep area is approximately $40 / 60 \%$.

Type 4: The distribution of the steep area is approximately $50 / 50 \%$. 
For types 1 and 2, apply nomogram A.
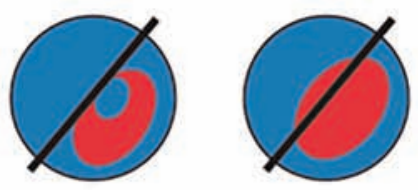

Nomogram A

Corneal asymmetry type 1 and 2

Please read implant calculation guidelines before using

\begin{tabular}{|c|c|c|c|c|c|c|c|c|c|c|c|c|c|}
\hline \multirow{9}{*}{ 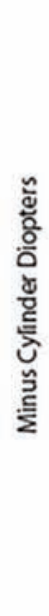 } & $\geq-8$ & $\begin{array}{r}90 / 200 \\
160 / 300\end{array}$ & $\begin{array}{r}90 / 200 \\
160 / 300\end{array}$ & $\begin{array}{r}90 / 200 \\
160 / 300\end{array}$ & $\begin{array}{r}90 / 200 \\
160 / 300\end{array}$ & $\begin{array}{r}90 / 200 \\
160 / 300\end{array}$ & $\begin{array}{r}90 / 200 \\
160 / 300\end{array}$ & $\begin{array}{c}90 / 200 \\
160 / 300\end{array}$ & $\begin{array}{r}90 / 250 \\
160 / 300\end{array}$ & $\begin{array}{c}90 / 250 \\
160 / 300\end{array}$ & $\begin{array}{r}90 / 250 \\
160 / 350\end{array}$ & $\begin{array}{r}90 / 250 \\
160 / 350\end{array}$ & $\begin{array}{c}90 / 250 \\
160 / 350\end{array}$ \\
\hline & -7 & $\begin{array}{r}90 / 200 \\
160 / 300\end{array}$ & $\begin{array}{r}90 / 200 \\
160 / 300\end{array}$ & $\begin{array}{r}90 / 200 \\
160 / 300\end{array}$ & $\begin{array}{r}90 / 200 \\
160 / 300\end{array}$ & $\begin{array}{r}90 / 200 \\
160 / 300\end{array}$ & $\begin{array}{r}90 / 200 \\
160 / 300\end{array}$ & $\begin{array}{r}90 / 200 \\
160 / 300\end{array}$ & $\begin{array}{r}90 / 200 \\
160 / 300\end{array}$ & $\begin{array}{r}90 / 200 \\
160 / 300\end{array}$ & $\begin{array}{r}90 / 200 \\
160 / 350\end{array}$ & $\begin{array}{r}90 / 200 \\
160 / 350\end{array}$ & $\begin{array}{c}90 / 200 \\
160 / 350\end{array}$ \\
\hline & -6 & $\begin{array}{r}90 / 150 \\
160 / 300 \\
\end{array}$ & $\begin{array}{r}90 / 150 \\
160 / 300 \\
\end{array}$ & $\begin{array}{r}90 / 150 \\
160 / 300 \\
\end{array}$ & $\begin{array}{r}90 / 150 \\
160 / 300 \\
\end{array}$ & $\begin{array}{r}90 / 150 \\
160 / 300 \\
\end{array}$ & $\begin{array}{r}90 / 150 \\
160 / 300 \\
\end{array}$ & $\begin{array}{r}90 / 150 \\
160 / 300 \\
\end{array}$ & $\begin{array}{r}90 / 150 \\
160 / 300 \\
\end{array}$ & $\begin{array}{r}90 / 150 \\
160 / 300 \\
\end{array}$ & $\begin{array}{r}90 / 200 \\
160 / 300 \\
\end{array}$ & $\begin{array}{r}90 / 150 \\
160 / 350 \\
\end{array}$ & $\begin{array}{r}90 / 150 \\
160 / 350 \\
\end{array}$ \\
\hline & -5 & $160 / 300$ & $160 / 300$ & $160 / 300$ & $160 / 300$ & $160 / 300$ & $160 / 300$ & $\begin{array}{r}90 / 150 \\
160 / 300\end{array}$ & $\begin{array}{r}90 / 150 \\
160 / 300\end{array}$ & $\begin{array}{r}90 / 150 \\
160 / 300\end{array}$ & $\begin{array}{r}90 / 150 \\
160 / 300\end{array}$ & $\begin{array}{l}120 / 200 \\
160 / 350\end{array}$ & $\begin{array}{l}120 / 200 \\
160 / 350\end{array}$ \\
\hline & -4 & $160 / 250$ & $160 / 250$ & $160 / 250$ & $160 / 250$ & $160 / 250$ & $160 / 250$ & $160 / 300$ & $\begin{array}{l}120 / 150 \\
160 / 300\end{array}$ & $\begin{array}{l}120 / 150 \\
160 / 300\end{array}$ & $\begin{array}{l}120 / 150 \\
160 / 300\end{array}$ & \begin{tabular}{|l|}
$120 / 250$ \\
$160 / 350$
\end{tabular} & $\begin{array}{l}120 / 250 \\
160 / 350\end{array}$ \\
\hline & -3 & $160 / 200$ & $160 / 200$ & $160 / 200$ & $160 / 200$ & $160 / 200$ & $160 / 200$ & $210 / 200$ & $210 / 250$ & $210 / 250$ & $210 / 300$ & $210 / 300$ & $210 / 300$ \\
\hline & -2 & $160 / 150$ & $160 / 150$ & $160 / 150$ & $160 / 150$ & $160 / 150$ & $160 / 150$ & $210 / 200$ & $210 / 200$ & $\begin{array}{l}160 / 150 \\
160 / 250 \\
\end{array}$ & $\begin{array}{l}160 / 200 \\
160 / 300 \\
\end{array}$ & $\begin{array}{l}160 / 200 \\
160 / 300 \\
\end{array}$ & $\begin{array}{l}160 / 250 \\
150 / 350 \\
\end{array}$ \\
\hline & -1 & $160 / 150$ & $160 / 150$ & $160 / 150$ & $160 / 150$ & $160 / 150$ & $160 / 150$ & $210 / 200$ & $\begin{array}{l}160 / 150 \\
160 / 200 \\
\end{array}$ & $\begin{array}{l}160 / 200 \\
160 / 250 \\
\end{array}$ & $\begin{array}{l}160 / 250 \\
160 / 300 \\
\end{array}$ & $\begin{array}{l}160 / 250 \\
160 / 300 \\
\end{array}$ & $\begin{array}{l}160 / 250 \\
160 / 350 \\
\end{array}$ \\
\hline & & +3 & +2 & +1 & Plano & $\begin{array}{l}-1 \\
\text { Mani }\end{array}$ & $\begin{array}{c}-\mathbf{2} \\
\text { Sphere }\end{array}$ & $\begin{array}{r}-3 \\
\text { ters }\end{array}$ & -4 & -5 & -6 & -7 & $\geq-8$ \\
\hline
\end{tabular}

Fig. 16: Nomogram A

For type 3, apply nomogram B.

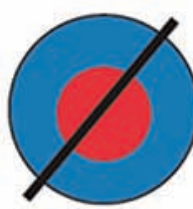

Nomogram B

Corneal asymmetry type 3

Please read implant calculation guidelines before using

\begin{tabular}{|c|c|c|c|c|c|c|c|c|c|c|c|c|}
\hline \multirow[b]{5}{*}{-6} & $\begin{array}{l}90 / 200 \\
120 / 300\end{array}$ & $\begin{array}{l}90 / 200 \\
120 / 300\end{array}$ & $\begin{array}{l}90 / 200 \\
120 / 300\end{array}$ & $\begin{array}{l}120 / 200 \\
120 / 300\end{array}$ & $\begin{array}{l}120 / 200 \\
120 / 300\end{array}$ & $\begin{array}{l}120 / 200 \\
120 / 300\end{array}$ & $\begin{array}{l}160 / 200 \\
160 / 300\end{array}$ & $\begin{array}{l}160 / 200 \\
160 / 300\end{array}$ & $\begin{array}{l}160 / 200 \\
160 / 300\end{array}$ & $\begin{array}{l}160 / 200 \\
160 / 300\end{array}$ & $\begin{array}{l}160 / 250 \\
160 / 350\end{array}$ & $\begin{array}{l}90 / 250 \\
160 / 350\end{array}$ \\
\hline & $90 / 200$ & $90 / 200$ & $90 / 200$ & $120 / 200$ & $120 / 200$ & $120 / 200$ & $160 / 200$ & $160 / 200$ & $160 / 200$ & $160 / 200$ & $160 / 250$ & $90 / 200$ \\
\hline & $120 / 300$ & $120 / 300$ & $120 / 300$ & $120 / 300$ & $120 / 300$ & $120 / 300$ & $160 / 300$ & $160 / 300$ & $160 / 300$ & $160 / 300$ & $160 / 350$ & $160 / 350$ \\
\hline & $90 / 200$ & $90 / 200$ & $90 / 200$ & $120 / 200$ & $120 / 200$ & $120 / 200$ & $160 / 200$ & $160 / 200$ & $160 / 200$ & $160 / 200$ & $160 / 250$ & $90 / 150$ \\
\hline & $120 / 300$ & $120 / 300$ & $120 / 300$ & $120 / 300$ & $120 / 300$ & $120 / 300$ & $160 / 300$ & $160 / 300$ & $160 / 300$ & $160 / 300$ & $160 / 350$ & $160 / 350$ \\
\hline \multirow[b]{2}{*}{-5} & $90 / 200$ & $90 / 200$ & $90 / 200$ & $120 / 200$ & $120 / 200$ & $120 / 200$ & $160 / 150$ & $160 / 200$ & $160 / 200$ & $160 / 200$ & $160 / 250$ & $120 / 200$ \\
\hline & $90 / 250$ & $90 / 250$ & $90 / 250$ & $120 / 250$ & $120 / 250$ & $120 / 250$ & $160 / 250$ & $160 / 300$ & $160 / 300$ & $160 / 300$ & $160 / 350$ & $160 / 350$ \\
\hline \multirow[b]{2}{*}{-4} & $90 / 150$ & $90 / 150$ & $90 / 150$ & $120 / 150$ & $120 / 150$ & $120 / 200$ & $160 / 150$ & $160 / 150$ & $160 / 150$ & $160 / 200$ & $160 / 250$ & $120 / 250$ \\
\hline & $90 / 200$ & $90 / 200$ & $90 / 200$ & $120 / 200$ & $120 / 200$ & $120 / 250$ & $160 / 250$ & $160 / 250$ & $160 / 250$ & $160 / 300$ & $160 / 350$ & $160 / 350$ \\
\hline \multirow[b]{2}{*}{-3} & $90 / 150$ & $90 / 150$ & $90 / 150$ & $120 / 150$ & $120 / 150$ & $120 / 150$ & $160 / 150$ & $160 / 150$ & $160 / 150$ & $160 / 200$ & $160 / 250$ & \\
\hline & $90 / 200$ & $90 / 200$ & $90 / 200$ & $120 / 200$ & $120 / 200$ & $120 / 200$ & $160 / 250$ & $160 / 250$ & $160 / 250$ & $160 / 300$ & $160 / 350$ & $210 / 300$ \\
\hline \multirow[b]{2}{*}{-2} & & & & & & & $160 / 150$ & $160 / 150$ & $160 / 200$ & $160 / 250$ & $160 / 250$ & $160 / 250$ \\
\hline & $160 / 150$ & $160 / 150$ & $160 / 150$ & $160 / 150$ & $160 / 150$ & $160 / 200$ & $160 / 200$ & $160 / 200$ & $160 / 200$ & $160 / 300$ & $160 / 300$ & $150 / 350$ \\
\hline \multirow{3}{*}{-1} & & & & & & & $160 / 150$ & $160 / 150$ & $160 / 200$ & $160 / 250$ & $160 / 250$ & $160 / 300$ \\
\hline & $160 / 150$ & $160 / 150$ & $160 / 150$ & $160 / 150$ & $160 / 150$ & $160 / 200$ & $160 / 200$ & $160 / 200$ & $160 / 250$ & $160 / 300$ & $160 / 300$ & $160 / 350$ \\
\hline & +3 & +2 & +1 & Plano & -1 & -2 & -3 & -4 & -5 & .6 & -7 & $\geq-8$ \\
\hline
\end{tabular}

Fig. 17: Nomogram B 
For type 4, apply nomogram C.

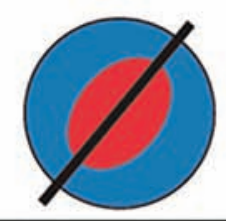

Nomogram C

Corneal asymmetry type 4

Please read implant calculation guidelines before using

KERARIIG INTRASTROMAL CORNEAL RING SEGMENTS

\begin{tabular}{|c|c|c|c|c|c|c|c|c|c|c|c|c|c|}
\hline \multirow{16}{*}{ 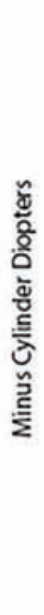 } & $\geq-8$ & $\begin{array}{l}120 / 250 \\
120 / 250\end{array}$ & $\begin{array}{l}120 / 250 \\
120 / 250\end{array}$ & $\begin{array}{l}120 / 250 \\
120 / 250\end{array}$ & $\begin{array}{l}120 / 250 \\
120 / 250\end{array}$ & $\begin{array}{l}120 / 300 \\
120 / 300\end{array}$ & $\begin{array}{l}160 / 250 \\
160 / 250\end{array}$ & $\begin{array}{l}160 / 300 \\
160 / 300\end{array}$ & $\begin{array}{l}160 / 300 \\
160 / 300\end{array}$ & $\begin{array}{l}160 / 300 \\
160 / 300\end{array}$ & $\begin{array}{l}160 / 350 \\
160 / 350\end{array}$ & $\begin{array}{l}160 / 350 \\
160 / 350\end{array}$ & $\begin{array}{l}160 / 350 \\
160 / 350\end{array}$ \\
\hline & \multirow[b]{2}{*}{-7} & $120 / 250$ & $120 / 250$ & $120 / 250$ & $120 / 250$ & $120 / 300$ & $160 / 250$ & $160 / 300$ & $160 / 300$ & $160 / 300$ & $160 / 350$ & $160 / 350$ & $160 / 350$ \\
\hline & & $120 / 250$ & $120 / 250$ & $120 / 250$ & $120 / 250$ & $120 / 300$ & $160 / 250$ & $160 / 300$ & $160 / 300$ & $160 / 300$ & $160 / 350$ & $160 / 350$ & $160 / 350$ \\
\hline & \multirow[b]{2}{*}{-6} & $90 / 300$ & $90 / 300$ & $90 / 300$ & $120 / 250$ & $120 / 250$ & $160 / 250$ & $160 / 300$ & $160 / 300$ & $160 / 300$ & $160 / 300$ & $160 / 350$ & $160 / 350$ \\
\hline & & $90 / 300$ & $90 / 300$ & $90 / 300$ & $120 / 250$ & $120 / 250$ & $160 / 250$ & $160 / 300$ & $160 / 300$ & $160 / 300$ & $160 / 300$ & $160 / 350$ & $160 / 350$ \\
\hline & \multirow[b]{2}{*}{-5} & $90 / 300$ & $90 / 300$ & $90 / 300$ & $120 / 250$ & $120 / 250$ & $160 / 250$ & $160 / 250$ & $160 / 300$ & $160 / 300$ & $160 / 300$ & $160 / 350$ & $160 / 350$ \\
\hline & & $90 / 300$ & $90 / 300$ & $90 / 300$ & $120 / 250$ & $120 / 250$ & $160 / 250$ & $160 / 250$ & $160 / 300$ & $160 / 300$ & $160 / 300$ & $160 / 350$ & $160 / 350$ \\
\hline & \multirow[b]{2}{*}{-4} & $90 / 250$ & $90 / 250$ & $90 / 250$ & $120 / 200$ & $120 / 200$ & $160 / 200$ & $160 / 250$ & $160 / 250$ & $160 / 300$ & $160 / 300$ & $160 / 350$ & $160 / 350$ \\
\hline & & $90 / 250$ & $90 / 250$ & $90 / 250$ & $120 / 200$ & $120 / 200$ & $160 / 200$ & $160 / 250$ & $160 / 250$ & $160 / 300$ & $160 / 300$ & $160 / 350$ & $160 / 350$ \\
\hline & \multirow[b]{2}{*}{$?$} & $90 / 200$ & $90 / 200$ & $90 / 200$ & $120 / 200$ & $120 / 200$ & $160 / 200$ & $160 / 200$ & $160 / 250$ & $160 / 250$ & $160 / 300$ & $160 / 350$ & $160 / 350$ \\
\hline & & $90 / 200$ & $90 / 200$ & $90 / 200$ & $120 / 200$ & $120 / 200$ & $160 / 200$ & $160 / 200$ & $160 / 250$ & $160 / 250$ & $160 / 300$ & $160 / 350$ & $160 / 350$ \\
\hline & & $90 / 150$ & $90 / 150$ & $90 / 150$ & $120 / 150$ & $120 / 150$ & $160 / 150$ & $160 / 200$ & $160 / 200$ & $160 / 250$ & $160 / 250$ & $160 / 300$ & $160 / 300$ \\
\hline & & $90 / 150$ & $90 / 150$ & $90 / 150$ & $120 / 150$ & $120 / 150$ & $160 / 150$ & $160 / 200$ & $160 / 200$ & $160 / 250$ & $160 / 250$ & $160 / 300$ & $160 / 300$ \\
\hline & \multirow{3}{*}{-1} & $90 / 150$ & $90 / 150$ & $90 / 150$ & $120 / 150$ & $120 / 150$ & $160 / 150$ & $160 / 150$ & $160 / 200$ & $160 / 250$ & $160 / 250$ & $160 / 300$ & $160 / 300$ \\
\hline & & $90 / 150$ & $90 / 150$ & $90 / 150$ & $120 / 150$ & $120 / 150$ & $160 / 150$ & $160 / 150$ & $160 / 200$ & $160 / 250$ & $160 / 250$ & $160 / 300$ & $160 / 300$ \\
\hline & & +3 & +2 & +1 & Plano & 1 & -2 & -3 & -4 & -5 & -6 & -7 & $z-8$ \\
\hline
\end{tabular}

Fig. 18: Nomogram C

The steps and measures to be taken for ICRS implantation in ectatic corneal disease are:

1. Obtain manifest subjective refraction.

2. Perform corneal topography (axial map).

3. Take pachymetry map. Determine the minimum corneal thickness at 5.5 and $6.5 \mathrm{~mm}$ optical zones.

4. Determine the steepest corneal meridian (SIM-K). If the refractive axis of the plus cylinder and the steepest topographic meridian do not match, select the topographic meridian.

5. Compare the thickness of the proposed segment according to the selected nomogram, with minimal corneal thickness obtained in the $6 \mathrm{~mm}$ optical zone. The thickness of the segment should not exceed $60 \%$ of the minimal corneal thickness. If it does, a segment with less thickness should be selected (Table 3).

Table 3: Safety thickness measurements for selection of intracorneal segment

\begin{tabular}{llllll}
\hline \multicolumn{5}{l}{ Safety limits } \\
\hline Proposed segment thickness & $150 \mu \mathrm{m}$ & $200 \mu \mathrm{m}$ & $250 \mu \mathrm{m}$ & $300 \mu \mathrm{m}$ & $350 \mu \mathrm{m}$ \\
Minimal corneal thickness required for implant & $250 \mu \mathrm{m}$ & $335 \mu \mathrm{m}$ & $420 \mu \mathrm{m}$ & $500 \mu \mathrm{m}$ & $580 \mu \mathrm{m}$ \\
\hline
\end{tabular}

Then we move on to select the reference meridian: If the CDVA $>0.5$, we select the steepest meridian corresponding with the plus refractive cylinder axis. If the CDVA $<0.5$, select the total coma aberration axis or the steepest meridian by topography (SIM-K). Then draw a line along the reference meridian selected.

To determine the treatment strategy: If the CVA $>0.4$, program the treatment based on refractive sphere and cylinder obtained by manifest refraction. If the CVA $<0.3$ or if the manifest refraction is not very reliable, program the treatment based on kerometric values.

When it comes to implantation, when the nomogram suggests using two segments, the nomogram data appearing in the top line of the box should be used for the segment implanted in the area where the ectasia is smaller (flatter meridian), and the data on the lower line shall be for the segment implanted on the steepest meridian (Example 1). When the nomogram suggests only one segment, this should be implanted on the steepest meridian, where the ectatic area is greater (Examples 2 and 3). If the keraring is positioned according to comatic aberration, do as in Example 4. All examples in Figure 19. 


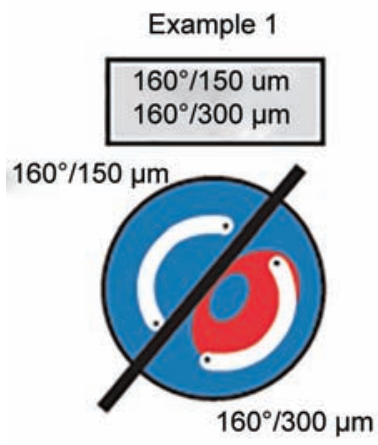

Example 2

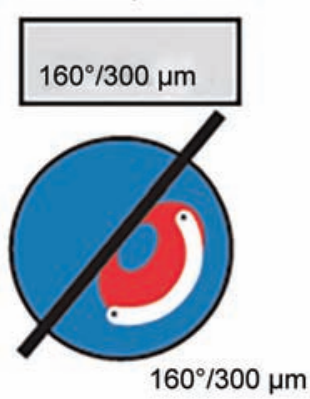

Example 3

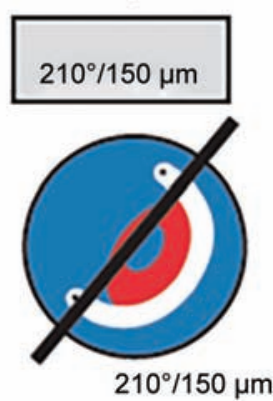

Example 4

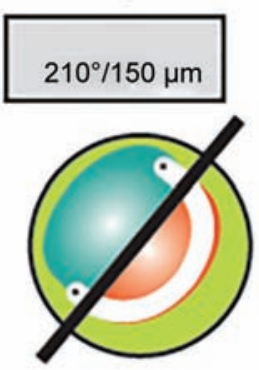

Fig. 19: Possible positions of intracorneal segment according to nomogram decision

These nomograms should be considered and used as a general guideline only and should be customized by the surgeon depending on the implant specifications for each patient and the results obtained.

We, also, have the Ferrara and Intacs implants (AJL Ophthalmic ${ }^{\circledR}$ ). In the case of Ferrara implants, a series of tasks must be performed before implantation (Table 4). The first step in selecting the ring is to define the type of keratoconus: sag, bowtie or nipple. Then, the distribution of the ectatic area in the cornea is determined: central (nipple and bowtie)—(50/50\%) or para-central (asymmetric) (0/100 25/75 and 33/66\%) (Table 5). The next step is to evaluate the preoperative corneal asphericity value $(\mathrm{Q})$. Then from topographic astigmatism, the thickness of the ring is defined (Tables 6 to 8). However, in the case of nipple keratoconus, this measurement is not used and the spherical equivalent is used to define the thickness of the ring, which should be a 210-arc ring (exclusive for this type of keratoconus) (Table 9). ${ }^{9}$

Finally, we must define the pachymetry at the incision site (steepest meridian of cornea). The depth of the incision should be $80 \%$ of the cornea thickness. This measurement is important to prevent superficial implants which could lead to future extrusion.

Table 4: Step-by-step

\begin{tabular}{ll}
\hline \multicolumn{1}{c}{ Ferrara ring nomogram: step-by-step } \\
\hline 1. Define the type of keratoconus: sag, bowtie or nipple \\
2. Distribution of the ectatic area in the cornea: $0 / 100,25 / 75,33 / 66$ and 50/50 \\
3. Corneal asphericity (Q) \\
4. Topographic astigmatism \\
5. Pachymetry at incision site and ring track
\end{tabular}

Table 5: Distribution of area of corneal ectasia

Distribution of ectasia
Sill the ectatic area is located at one side of the cornea
$33 / 66 \%$

Table 6: Segment thickness choice in symmetric bowtie keratoconus

\begin{tabular}{ll}
\hline Topographic astigmatism $(D)$ & Intracorneal segment thickness \\
\hline$<2.00$ & $150 / 150$ \\
2.25 to 4.00 & $200 / 200$ \\
4.25 to 6.00 & $250 / 250$ \\
$>6.25$ & $300 / 300$ \\
\hline
\end{tabular}


Table 7: Segment thickness choice in sag keratoconus with $0 / 100$ and 25/75\% asymmetry index

\begin{tabular}{ll}
\hline Topographic astigmatism $(D)$ & Intracorneal segment thickness \\
\hline$<2.00$ & None/150 \\
2.25 to 4.00 & None/200 \\
4.25 to 6.00 & None/250 \\
6.25 to 8.00 & None/300 \\
8.25 to 10.00 & $150 / 250$ \\
$>10$ & $200 / 300$ \\
\hline
\end{tabular}

Table 8: Segment thickness choice in sag keratoconus with $0 / 100$ and $33 / 66 \%$ asymmetry index

\begin{tabular}{ll}
\hline Topographic astigmatism $(D)$ & Intracorneal segment thickness \\
\hline$<2.00$ & none/150 \\
4.25 to 6.00 & $200 / 250$ \\
$<2.00$ & none/150 \\
4.25 to 6.00 & $200 / 250$ \\
\hline
\end{tabular}

Table 9: Segment thickness choice in nipple keratoconus $(210 \mu \mathrm{m})$

\begin{tabular}{ll}
\hline Spherical equivalent $(D)$ & Intracorneal segment thickness \\
\hline$>2.00$ & 150 \\
2.25 to 4.00 & 200 \\
4.25 to 6.00 & 250 \\
$>6.25$ & 300 \\
\hline
\end{tabular}

Regarding intacs, the recommendation is to select between symmetric or asymmetric segments depending on the ectatic area and spherical and cylindrical refractive power.

- Use symmetric segments when the ectatic area is within the 3 to $5 \mathrm{~mm}$ central optical zone and when, in the manifest refraction with the positive cylinder, the spherical power is greater than the cylindrical power (Table 10).

- Use asymmetric segments when the ectatic area is outside the $3 \mathrm{~mm}$ geometric center and when, in the manifest refraction with the positive cylinder, the cylindrical power is greater than the spherical power (Table 11).

Table 10: Symmetric segment thickness

\begin{tabular}{lll}
\hline Spherical power & Inferior intacs & Superior intacs \\
\hline-0.00 to $-1.00 \mathrm{D}$ & $0.210 \mathrm{~mm}$ & $0.210 \mathrm{~mm}$ \\
-1.00 to $-1.75 \mathrm{D}$ & $0.250 \mathrm{~mm}$ & $0.250 \mathrm{~mm}$ \\
-2.00 to $-2.75 \mathrm{D}$ & $0.300 \mathrm{~mm}$ & $0.300 \mathrm{~mm}$ \\
-3.00 to $-3.75 \mathrm{D}$ & $0.350 \mathrm{~mm}$ & $0.350 \mathrm{~mm}$ \\
-4.00 to $-4.75 \mathrm{D}$ & $0.400 \mathrm{~mm}$ & $0.400 \mathrm{~mm}$ \\
$>-5.00 \mathrm{D}$ & $0.450 \mathrm{~mm}$ & $0.450 \mathrm{~mm}$ \\
\hline
\end{tabular}

Table 11: Asymmetric segment thickness

\begin{tabular}{lll}
\hline Cylindrical power & Inferior intacs & Superior intacs \\
\hline 2.00 to $3.00 \mathrm{D}$ & $0.350 \mathrm{~mm}$ & $0.210 \mathrm{~mm}$ \\
3.00 to $4.00 \mathrm{D}$ & $0.400 \mathrm{~mm}$ & $0.210 \mathrm{~mm}$ \\
4.00 and higher & $0.450 \mathrm{~mm}$ & $0.210 \mathrm{~mm}$ \\
\hline
\end{tabular}

Finally, with myoring $\left(\mathrm{DIOPTEX} \mathrm{X}^{\circledR}\right)$ implants some inclusion criteria must be met before its nomogram can be applied:

- Inclusion criteria:

1. Uncorrected visual acuity (UCVA) < 0.3 (20/60; LogMAR 0.5).

2. Minimal corneal thickness $>360$ micron.

3. Average central keratometry $(\mathrm{ACK})(\mathrm{K} 1+\mathrm{K} 2) / 2>44 \mathrm{D}$.

4. No central corneal scarring.

5. No history of anterior corneal surgery.

6. Age $<50$ years. 
7. Surgeon trained in corneal intrastromal implantation system (CISIS).

Once these inclusion criteria are met, the nomogram (Table 12) for this device is the following:

Table 12: Myoring nomogram

\begin{tabular}{lll}
\hline Average central keratometry $(\mathrm{D})$ & Implant diameter $(\mathrm{mm})$ & Implant thickness $($ micro) \\
\hline $\mathrm{ACK}<44$ & 7 & 280 \\
$44<\mathrm{ACK}<48$ & 6 & 240 \\
$48<\mathrm{ACK}<52$ & 6 & 280 \\
$52<\mathrm{ACK}<55$ & 5 & 280 \\
$55<\mathrm{ACK}$ & 5 & 320 \\
\hline
\end{tabular}

Our research team is currently conducting a process to optimize implantation of the above-mentioned intracorneal segments by developing a database with over 1,000 cases of keratoconus and creating software (K\&A corneal ectasia treatment simulator ${ }^{\circledR}$ ) based on a neural network of clinical cases which will enable more accurate action to be taken in the treatment of keratoconus.

Before implantation of any of the intracorneal segments mentioned above, we must take a number of preoperative indications into account, ${ }^{10}$ in order to increase the likelihood of attaining the best possible postoperative outcomes for the patient:

1. CVA $<0.9$.

2. Stable cases: Patients with refractive and topographic stability, confirmed in the past 12 months.

3. Aligning of refractive and keratometric axes. The least curved meridian of the cornea (K1) should be aligned with the refractive cylinder axis (expressed as a negative value). When the meridian and the axis form an angle of between 0 and $15^{\circ}$ they are considered properly aligned.

4. Internal astigmatism $<3 \mathrm{D}$.

5. Corneal pachymetry in tunnel area $>300 \mu \mathrm{m}$ (Ferrara); $>450 \mu \mathrm{m}$ (Intacs); $>250 \mu \mathrm{m}$ (Keraring), with these being minimum thicknesses depending on the thickness of each intracorneal segment.

6. Absence of corneal leukoma.

Despite the preoperative indications described in our center, $100 \%$ predictability is still not possible in postoperative results due to changes in corneal biomechanics. This was observed by our research team on conducting a multiple regression analysis. ${ }^{11}$ According to this analysis, several factors appear to be involved in the ring segment effect, revealing the need for a more complex analysis. Therefore, a multiple linear regression was performed to find the appropriate mathematical expression relating to all factors that may be involved. To obtain this mathematical model, a model that considered visual refraction, keratometric data, intracorneal segment thicknesses values and corneal aberrations values was calculated.

1. SST $(\mu \mathrm{m})=132.20-12.14 \times$ CYLp $-20.47 \times$ DifKM $+24.37 \times$ DifRMSHOA $-0.74 \times$ DifIST

2. IST $(\mu \mathrm{m})=132.20-12.14 \times$ CYLp $-20.47 \times$ DifKM $+24.37 \times$ DifRMSHOA $+0.26 \times$ DifIST

Where SST is the superior segment thickness, IST the inferior segment thickness, CYLp the preoperative cylinder, DifKM the change in mean keratometry after surgery, DifIST the difference between the thickness of the inferior and superior ring segments, and DifRMSHOA the change in the RMS value for corneal higher-order aberrations.

In fact, in a previous paper, our research group found a significant correlation between the corneal resistance factor (CRF), measured using an ocular response analyser (ORA; Reichert) and the magnitude of the corneal spherical-like aberrations. ${ }^{12}$

It has, thus, been shown that the visual outcomes post-ICRS implantation correlated inversely with the magnitude of some corneal higher-order aberrations. It should, therefore, be considered that larger amounts of corneal higher-order aberrations are an important factor especially in advanced keratoconic corneas where biomechanical alteration would be more pronounced. Therefore, the predictability models could be improved if high order corneal aberrations were included. In other words, the introduction of the aberrometric factor could be an indirect manner of considering part of the biomechanical corneal factor. In any case, this indirect contribution of aberrometry to corneal biomechanics is limited, and it does not account for the total biomechanical effect.

The reason for this is that the analysis of the corneal biomechanical properties of the cornea in vivo is not an easy task in clinical practice and we also have to remember that the exact contributions of the elastic and viscous components to the magnitude of these parameters are not yet fully understood. 
Our research team is currently engaged on optimizing the implant of the intracorneal segments mentioned above. We have created a data base of more than 1.000 keratoconus cases and a new software (K\&A keratoconus correction program $^{\circledR}$ ), based on a neural network that allows clinical cases to have a more precise potential action in the treatment of keratoconus.

\subsection{Advantages and Disadvantages of Intracorneal Segment Implants}

Segments have the advantage that they can be removed in the event of failure and can be combined with other techniques, such as cross-linking, PRK and phakic intraocular lenses ${ }^{8}$ and keratoplasty procedures. Also, they can also be exchanged for segments with different characteristics, making it possible to improve results when these prove unfavorable.

A multicenter study conducted by our research team determined the result of ICRS implantation based on the patient's visual function. ${ }^{1}$ In this study, a total of 268 patients with keratoconus underwent ICRS implantation and were followed-up for 6 months. The classification used was the RETICS classification as described earlier.

The following success and failure criteria were defined in order to determine the efficacy of the surgical procedure:

Success was defined as cases that had the following characteristics 6 months post-ICRS implantation:

- Increase of 1 or more lines of corrected or uncorrected vision

- Reduction of 2D or more in the spherical equivalent

- Reduction of at least 1 micron in higher-order corneal aberrations or coma-like aberrations

Meanwhile, failure criteria were as follows:

- Reduction of 1 or more lines of corrected or uncorrected vision

- Increase of 2D or more in the spherical equivalent

- Increase of at least 1 micron in higher-order corneal aberrations or coma-like aberrations.

With regard to uncorrected distance visual acuity (UDVA), all patients experienced significant improvement in UDVA at 6 months regardless of their keratoconus grade $(p<0.05)$. However, when analysing the changes found in corrected distant visual acuity (CDVA), patients with the mildest forms of keratoconus-those classified as Grade I-showed a significant loss $(\mathrm{p}<0.01)$ in CDVA 6 months post-ICRS implantation. All other patients had a significant improvement $(\mathrm{p}<0.05)$ in CDVA after the surgical procedure, as shown in the Table 13.

Table 13: Results in CDVA according to RETICS classification

\begin{tabular}{llll}
\hline CDVA & Pre & Six months & $p$-value \\
\hline Grade I & $0.97 \pm 0.06$ & $0.86 \pm 0.18$ & $<0.01$ \\
Grade II & $(0.90$ to 1.15$)$ & $(0.40$ to 1.20$)$ & 0.04 \\
Grade III & $0.71 \pm 0.08$ & $0.75 \pm 0.22$ & $<0.01$ \\
& $(0.60$ to 0.86$)$ & $(0.30$ to 1.20$)$ & $<0.01$ \\
Grade IV & $0.45 \pm 0.53$ & $0.57 \pm 0.22$ & $(0.10$ to 1.00$)$ \\
Grade plus & $(0.40$ to 0.58$)$ & $0.50 \pm 0.22$ & $<0.01$ \\
& $0.27 \pm 0.05$ & 0.05 to 1.00$)$ & $(0.05$ to 1.00$)$ \\
\hline
\end{tabular}

The study also analyzed topographical changes after ICRS implantation according to the visual impairment of patients with keratoconus. Table 14 summarizes the topographical results found in this study. Although we were able to demonstrate a significant reduction in all keratometry measurements in all groups $(\mathrm{p}<0.01)$, the greatest reduction was in patients classified as grade plus, i.e. those with the most severe form of the disease.

Table 14: Topographic results according to RETICS classification

\begin{tabular}{|c|c|c|c|c|c|c|c|c|c|}
\hline & \multicolumn{2}{|c|}{$K 1$} & \multirow[b]{2}{*}{$p$-value } & \multicolumn{2}{|c|}{$K 2$} & \multirow[b]{2}{*}{$p$-value } & \multicolumn{2}{|c|}{$K m$} & \multirow[b]{2}{*}{$p$-value } \\
\hline & Pre & Six months & & Pre & Six months & & Pre & Six months & \\
\hline Grade I & $\begin{array}{l}43.75 \pm 2.95 \\
(36.22 \text { to } \\
49.10)\end{array}$ & $\begin{array}{l}41.95 \pm 2.13 \\
(35.50 \text { to } \\
46.10)\end{array}$ & $<0.01$ & $\begin{array}{l}45.91 \pm 3.87 \\
(36.00 \text { to } \\
58.82)\end{array}$ & $\begin{array}{l}44.71 \pm 2.20 \\
(41.56 \text { to } \\
49.38)\end{array}$ & $<0.01$ & $\begin{array}{l}44.90 \pm 2.96 \\
(35.65 \text { to } \\
54.96)\end{array}$ & $\begin{array}{l}43.35 \pm 1.69 \\
(38.63 \text { to } \\
47.45)\end{array}$ & $<0.01$ \\
\hline Grade II & $\begin{array}{l}45.09 \pm 4.44 \\
(34.07 \text { to } \\
56.00)\end{array}$ & $\begin{array}{l}43.17 \pm 4.47 \\
(33.46 \text { to } \\
53.94)\end{array}$ & $<0.01$ & $\begin{array}{l}47.41 \pm 5.42 \\
(34.10 \text { to } \\
65.09)\end{array}$ & $\begin{array}{l}46.08 \pm 5.25 \\
(34.10 \text { to } \\
59.23)\end{array}$ & $<0.01$ & $\begin{array}{l}46.24 \pm 4.13 \\
(34.57 \text { to } \\
59.10)\end{array}$ & $\begin{array}{l}44.52 \pm 4.41 \\
(34.32 \text { to } \\
56.10)\end{array}$ & $<0.01$ \\
\hline
\end{tabular}

Contd.... 


\begin{tabular}{|c|c|c|c|c|c|c|c|c|c|}
\hline Grade III & $\begin{array}{l}48.10 \pm 6.00 \\
(33.37 \text { to } \\
74.69)\end{array}$ & $\begin{array}{l}44.56 \pm 4.90 \\
(32.45 \text { to } \\
54.49)\end{array}$ & $<0.01$ & $\begin{array}{l}49.88 \pm 6.71 \\
(37.25 \text { to } \\
83.67)\end{array}$ & $\begin{array}{l}47.68 \pm 5.68 \\
(32.75 \text { to } \\
64.06)\end{array}$ & $<0.01$ & $\begin{array}{l}48.93 \pm 5.67 \\
(36.25 \text { to } \\
78.80)\end{array}$ & $\begin{array}{l}46.09 \pm 5.07 \\
(32.60 \text { to } \\
59.52)\end{array}$ & $<0.01$ \\
\hline Grade IV & $\begin{array}{l}51.41 \pm 6.69 \\
(31.50 \text { to } \\
69.40)\end{array}$ & $\begin{array}{l}45.94 \pm 4.62 \\
(38.00 \text { to } \\
58.02)\end{array}$ & $<0.01$ & $\begin{array}{l}51.89 \pm 6.69 \\
(33.80 \text { to } \\
74.48)\end{array}$ & $\begin{array}{l}49.34 \pm 5.74 \\
(41.76 \text { to } \\
62.20)\end{array}$ & $<0.01$ & $\begin{array}{l}51.65 \pm 6.06 \\
(32.65 \text { to } \\
72.70)\end{array}$ & $\begin{array}{l}47.64 \pm 4.87 \\
(39.88 \text { to } \\
60.11)\end{array}$ & $<0.01$ \\
\hline $\begin{array}{l}\text { Grade } \\
\text { plus }\end{array}$ & $\begin{array}{l}53.13 \pm 8.10 \\
(32.20 \text { to } \\
79.08)\end{array}$ & $\begin{array}{l}47.73 \pm 4.97 \\
(35.37 \text { to } \\
59.10)\end{array}$ & $<0.01$ & $\begin{array}{l}55.68 \pm 9.15 \\
(38.10 \text { to } \\
85.51)\end{array}$ & $\begin{array}{l}50.24 \pm 5.11 \\
(40.40 \text { to } \\
61.93)\end{array}$ & $<0.01$ & $\begin{array}{l}54.40 \pm 8.00 \\
(38.48 \text { to } \\
82.62)\end{array}$ & $\begin{array}{l}48.81 \pm 4.39 \\
(39.54 \text { to } \\
57.34)\end{array}$ & $<0.01$ \\
\hline
\end{tabular}

We observed that there were no significant differences in the percentage of patients who gained or lost UDVA lines; reduced or increased spherical equivalent by 2D or more; or increased or reduced asymmetric corneal aberrations or higher-order aberrations by 1 or more microns. However, when analyzing success and failure rates related to the percentage of patients who gained or lost lines of CDVA, the results were significantly different when evaluated according to the degree of visual impairment (Table 15). As shown, the success or failure rate of ICRS implantation is directly related to patients' visual impairment at the time of the surgical procedure. Thus, $85 \%$ of patients classified as grade plus will gain at least one line of CDVA 6 months following implantation of ICRS, while only $13.5 \%$ of patients classified as grade I will achieve the same results. Similarly, over half of the patients classified as grade I will lose at least one line of CDVA after the surgery and only $11 \%$ of patients classified as grade plus will experience the same results.

Table 15: Success and failure rates according to RETICS grading

\begin{tabular}{lll}
\hline KCN & Success CDVA (\%) & Failure CDVA (\%) \\
\hline Grade I & 13.5 & 51.0 \\
Grade II & 49.4 & 29.8 \\
Grade III & 54.0 & 18.9 \\
Grade IV & 81.3 & 9.3 \\
Grade plus & 85.1 & 11.1 \\
\hline
\end{tabular}

Likewise, when we compare the success and failure rates of patients with the mildest form of the disease (CDVA $\geq 0.6$, grades I and II) to the results of patients with the most severe grades of keratoconus (CDVA $\leq 0.4$, grades IV and plus), we find that there are statistically significant differences $(p<0.01)$ and that the patients who most benefit from ICRS implants are those who have the greatest visual impairment at the time of surgery (Table 16).

Table 16: Comparison of success and failure rates according to the degree of visual impairment

\begin{tabular}{|c|c|c|c|}
\hline$K C N$ & $\begin{array}{l}\text { Success } \\
\text { Increase } \geq 1 \text { CDVA line }\end{array}$ & $\begin{array}{l}\text { Failure } \\
\text { Loss } \geq 1 \text { CDVA line }\end{array}$ & $\begin{array}{l}\text { Loss } \geq 2 \\
\text { CDVA line }\end{array}$ \\
\hline CDVA $\geq 0.6$ grade $I$ and $I I$ & $37.90 \%$ & $36.29 \%$ & $25.80 \%$ \\
\hline CDVA $\leq 0.4$ grade IV and Plus & $82.85 \%$ & $10.00 \%$ & $4.28 \%$ \\
\hline
\end{tabular}

After analyzing these results, we can conclude that patients who most benefit from ICRS implantation are those who have the greatest visual impairment at the time of surgery. Special attention should be paid to cases with good visual function because of the risk of losing lines of vision. This is because patients with good vision are those who have 'little to gain and much to lose'. Other factors related to these results may include biomechanical changes or changes in the refractive index that occur in the corneal stroma after implantation. The latter would need to be corroborated in future research where these variables are analyzed.

\section{REFERENCES}

1. Vega-Estrada A, Alió JL, Brenner LF, Javaloy J, Plaza Puche AB, Barraquer RI, Teus MA, Murta J, Henriques J, Uceda-Montanes A. Outcomes analysis of intracorneal ring segments for the treatment of keratoconus based on visual, refractive and aberrometric impairment. Am J Ophthalmol 2013;155(3):575-584.

2. Meek KM, Hayes S. Corneal cross-linking—a review. Ophthalmic Physiol Opt 2013 Mar;33(2):78-93.

3. Vega-Estrada A, Alió JL, Plaza Puche AB, Marshall J. Outcomes of a new microwave procedure followed by accelerated crosslinking for the treatment of keratoconus: a pilot study. J Refract Surg 2012;28(11):787-793.

4. Colin J, Cochener B, Savary G, Malet F. Correcting keratoconus with intracorneal rings. J Cataract Refract Surg 2000;26(8):1117-1122.

5. Coskunseven E, Kymionis GD, Tsiklis NS, et al. One-year results of intrastromal corneal ring segment implantation (KeraRing) using femtosecond laser in patients with keratoconus. Am J Ophthalmol 2008;145(5):775-779. 
6. Ertan A, Kamburoglu G. Intacs implantation using femtosecond laser for management of keratoconus: comparison of 306 cases in different stages. J Cataract Refract Surg 2008;34(9):1521-1526.

7. Shabayek MH, Alió JL. Intrastromal corneal ring segment implantation by femtosecond laser for keratoconus correction. Ophthalmol 2007;114(9):1643-1652.

8. Alió JL, Piñero DP, Söğütlü E, Kubaloglu A. Implantation of new intracorneal ring segments after segment explanation for unsuccessful outcomes in eyes with keratoconus. J Cataract Refract Surg 2010;36(8):1303-1310.

9. Miranda D, Sartori M, Francesconi C, Allemann N, Ferrara P, Campos M. Ferrara intrastromal corneal ring segments for severe keratoconus. J Refract Surg 2003;19(6):645-653.

10. Peña-García P, Alió JL, Vega-Estrada A, Barraquer RI. Internal, Corneal and refractive astigmatism as prognostic factor for ICRS implantation in mild to moderate keratoconus. J Cataract Refract Surg 2014;40(10):1633-1644.

11. Piñero DP, Alió JL, Teus MA, Barraquer RI, Uceda-Montañés A. Modeling the intracorneal ring segment effect in keratoconus using refractive, keratometric, and corneal aberrometric data. Invest Ophthalmol Vis Sci 2010 Nov;51(11):5583-5591.

12. Piñero DP, Alió JL, Barraquer RI, Michael R, Jimenez R. Corneal biomechanics, refraction and corneal aberrometry in keratoconus: an integrated study. Invest Ophthalmol Vis Sci 2010;51:1948-1955.

13. Alió JL, Piñero DP, Daxer A. Clinical outcomes after complete ring implantation in corneal ectasia using the femtosecond technology: a pilot study. Ophthalmol 2011 Jul;118(7):1282-1290.

14. Rabinowitz YS. INTACS for keratoconus. Int Ophthalmol Clin 2006;46(3):91-103.

15. Ertan A, Kamburoglu G, Akgun U. Comparison of outcomes of 2 channel sizes for intrastromal ring segment implantation with a femtosecond laser in eyes with keratoconus. J Cataract Refract Surg 2007;33:648-653.

\section{INDICATIONS OF COMBINED INTRACORNEAL SEGMENTS AND CROSS-LINKING THERAPY}

One of the main limitations of CXL is that, even if disease progression is halted, the morphological changes in a cornea due to keratoconus are not altered, so there is no significant refractive or visual effect. ${ }^{1}$ As a result, ICRS implantation is performed in order to regularize corneal geometry with the aim of providing a refractive and molding effect that would otherwise not occur with the use of CXL alone. ${ }^{2}$

This combination of CXL and intracorneal segment implantation has been performed by several research groups. Vincent and Boxer Wachler ${ }^{7}$ conducted a 3-year retrospective study analyzing the results of 14 eyes that underwent same-day transepithelial CXL and Intacs implantation. The mean CVA improved from 20/32 preoperatively to 20/25 postoperatively during a follow-up of 3 years. All keratometry values improved significantly. The authors demonstrated that patients with advanced keratoconus had greater improvement in CVA compared with earlier forms of keratoconus.

Ertan et al reported improvements in UCVA, cylinder, sphere and keratometry, considering that Intacs implantation with transepithelial CXL is effective in eyes with keratoconus and it may be considered as a process of stabilization and improvement. ${ }^{8}$ Saelens et al implanted Ferrara intracorneal rings in patients with progressive keratoconus and then applied cross-linking in the intrastromal canals. After 1 year of follow-up, there was one explantation due to partial extrusion. The mean UCVA improved from $0.10 \pm 0.07$ to $0.6 \pm 0.24$ and CVA improved from $0.56 \pm 0.08$ to 0.82 \pm 0.25 . ${ }^{9}$ Coskunseven et al found that implanting intracorneal rings followed by CXL resulted in an improvement of postoperative keratoconus parameters (CVA, spherical equivalent, keratometric values) ${ }^{10}$

Indications for combined CXL + ICRS treatment in patients with keratoconus are:

- Clinical signs of progressive keratoconus ${ }^{3}$

- Corrected visual acuity of 0.8 (20/25; LogMAR 0.1) or worse ${ }^{1}$

- Corneal thickness greater than 400 microns $^{3}$

- Intolerance to or poorly motivated to wear contact lenses ${ }^{3}$

- Sociogeographic reasons (patients who for some reason cannot attend regular eye examinations)

- In more stable cases, with a more regular cornea in the center, it is best to first perform ICRS implantation and then CXL.

Contraindications:

- Pregnancy and breastfeeding ${ }^{4,5}$

- Patients with corrected visual acuity over $0.8(20 / 25 ; \text { LogMAR } 0.1)^{6}$

- Corneal thickness less than 400 microns $^{3}$

- Corneal leukoma. ${ }^{2}$

\section{REFERENCES}

1. Spoerl E, Mrochen M, Sliney D, Trokel S, Seiler T. Safety of UVA-riboflavin cross-linking of the cornea. Cornea 2007;26:385-389.

2. Chan CC, Sharma M, Wachler BS. Effect of inferior-segment Intacs with and without C3-R on keratoconus. J Cataract Refract Surg. 2007 Jan;33(1):75-80. 
3. Coskunseven E, Jankov MR 2nd, Hafezi F, Atun S, Arslan E, Kymionis GD. Effect of treatment sequence in combined intrastromal corneal rings and corneal collagen cross-linking for keratoconus. J Cataract Refract Surg 2009 Dec;35(12):2084-2091.

4. Raiskup F, Spoerl E. Corneal cross-linking with riboflavin and ultraviolet A. Part II. Clinical indications and results. Ocul Surf 2013 Apr;11:93-108.

5. Hafezi F, Iseli HP. Pregnancy-related exacerbation of iatrogenic keratectasia despite corneal collagen cross-linking. J Cataract Refract Surg 2008;34:1219-1221.

6. Vega-Estrada A, Alió JL, Brenner LF, Javaloy J, Plaza Puche AB, Barraquer RI, Teus MA, Murta J, Henriques J, Uceda-Montanes A. Outcome analysis of intracorneal ring segments for the treatment of keratoconus based on visual, refractive and aberrometric impairment. Am J Ophthalmol 2013 Mar;155(3):575-584.

7. Vicente LL, Boxer Wachler BS. Factors that correlate with improvement in vision after combined Intacs and transepithelial corneal cross-linking. Br J Ophthalmol 2010;94:1597-1601.

8. Ertan A, Karacal H, Kamburoglu G. Refractive and topographic results of transepithelial cross-linking treatment in eyes with intacs. Cornea 2009;28:719-723.

9. Saelens IE, Bartels MC, Bleyen I, Van Rij G. Refractive, topographic, and visual outcomes of same-day corneal cross-linking with Ferrara intracorneal ring segments in patients with progressive keratoconus. Cornea 2011;30:1406-408.

10. Coskunseven E, Jankov MR 2nd, Hafezi F, et al. Effect of treatment sequence in combined intrastromal corneal rings and corneal collagen cross-linking for keratoconus. J Cataract Refract Surg 2009;35:2084-2091.

\section{REFRACTIVE KERATOCONUS MANAGEMENT}

The use of keratoconus surgery for refractive purposes has been discussed by several authors in medical literature. The two primary lines of action are phakic lens implantation ${ }^{1-6}$ and corneal tissue ablation using photorefractive keratectomy. The latter technique is usually combined with cross-linking. ${ }^{7-13}$

Both are normally used in patients with forme fruste or frank, but stable, keratoconus ${ }^{6}$ and are not the techniques of choice in progressive patients, although there are some studies along these lines.

These techniques have also been used in combination with ICRS implantation. ${ }^{16,17}$

In accordance with our research, we believe that this type of surgery should be reserved solely for stable patients. Thus, it is essential to define the stability criteria, as the literature does not contain uniform indications generally followed by different authors.

\subsection{Stability Criteria}

We have always followed the same stability criteria in our work. If one (or several) of the circumstances described below occurs in an interval of less than 1 year, keratoconus is considered progressive:

- Increase in astigmatism of $1.0 \mathrm{D}$ or more

- Significant changes in the orientation of refractive axes

- Increase of $1.0 \mathrm{D}$ or more in the optical power of the steepest corneal meridian

- Decrease of 25 microns or more in corneal thickness.

\subsection{Phakic Lenses}

The use of phakic lenses has advantages, such as efficient and stable ametropia compensation, preservation of accommodation, centered and rotational stability not dependent on corneal morphology, retinal image magnification in patients with high myopia, and reversibility in the event of failure.

Negative effects of phakic lens implantation include accelerated endothelial cell loss, cataract formation, pupil ovalisation, lens rotation or decentration, photic phenomena and retinal detachment in isolated cases.

\subsubsection{Implantation Criteria}

Based on our experience and that described in medical literature, we believe the following criteria should be met for phakic lens implantation in keratoconus:

1. Disease stability, as detailed earlier, for at least the previous 2 years.

2. Corrected visual acuity equal to or better than 0.4 (decimal scale).

3. Spherical equivalent greater than $-2.75 \mathrm{D}$.

4. Absence of clinically significant irregular astigmatism. We consider irregular astigmatism to be clinically significant when there is a difference greater than one line of corrected vision between the vision obtained with glasses and the vision obtained with hard contact lenses. 
According to a recent study by our group with the largest number of case studies on phakic lens implantation in keratoconus reported to date, ${ }^{6}$ the safety of this procedure in visual terms is high (post CDVA/pre CDVA $=1.19$ \pm 0.29 ). It is also an effective operation (post UDVA/pre CDVA $=0.90 \pm 0.26$ ). In fact, many patients stopped wearing glasses after phakic lens implantation. These results are roughly consistent with those reported by other authors. ${ }^{1-5}$

It is also interesting to note that, based on the results of this study, implantation of a foldable lenses can be as safe and effective as implantation of a hard lens. The following models were studied: foldable Artiflex lens (Ophtec, Netherlands) and the ICL (implantable collamer lens, STAAR Surgical, United States). This result is particularly interesting, because flexible lenses can be inserted and removed through smaller incisions thanks to their flexibility.

We recommend that, whenever possible, implantation be performed using this type of microincision surgery (with incision of 1.8-2.00 mm) to ensure that the ectatic process is not affected as a result of the operation. It has been widely demonstrated that use of this type of incision causes minimal alternations in the cornea. ${ }^{18,19}$

\subsection{Excimer Laser Correction}

Photorefractive keratectomy (PRK) for the treatment of keratoconus has been discussed by several authors. While the precision obtained in ablating the corneal surface with laser ablation may be very high in normal corneas, it is unclear whether the same occurs with keratoconic patients due to pre-existing corneal asymmetry and to the reduced reliability and repeatability of keratometry measurements in such patients. ${ }^{20}$ In addition, ablating corneal tissue in patients whose corneal biomechanics are already altered is a risk factor to bear in mind. Obviously, unlike phakic lenses, this technique cannot be used to treat high levels of myopia (which are frequent in keratoconus), because the ablation is so deep in these cases. Furthermore, this technique is not reversible.

We, therefore, believe this is not the technique of choice and should at least be combined with cross-linking.

Our experience shows that it is a safe technique $(1.03 \pm 0.08)$ with a high degree of effectiveness $(0.91 \pm 0.18)$, but we have only been able to confirm these results in the short-term. Moreover, we detected some cases in which the ectasia became progressive. Hence, the need for combined use with cross-linking and for more cases studies with longer follow-up.

Interestingly, regarding the use of this surgery on keratonic eyes, some authors like Vinciguerra et $\mathrm{al}^{21}$ suggest using corneal topography data before epithelial removal to avoid the masking effect over the stroma that may occur in keratoconus. This is obviously an inconvenient practice for the patient, but a well-founded one in our opinion.

Lastly, regarding the ablation profile to use, we think it is better to use wavefront-guided ablation as opposed to topography-guided ablation. This is because with the latter technique the operation is conducted based on the aberrometric profile of the anterior corneal surface. As has been widely reported in the literature, high internal astigmatism is common in keratoconic eyes due to large disparities between the anterior and posterior corneal surfaces. ${ }^{22,23}$ For this reason, we believe it is better to use a customized wavefront profile.

In any case, as stated above, we do not consider PRK on its own to be the technique of choice in keratoconus, despite the high efficacy rates obtained (in a small series of only 21 eyes), due to doubts concerning long-term stability. ${ }^{24}$

\section{REFERENCES}

1. Sedaghat M, Ansari-Astaneh MR, Zarei-Ghanavati M, Davis SW, Sikder S. Artisan iris-supported phakic IOL implantation in patients with keratoconus: a review of 16 eyes. J Refract Surg 2011 Jul;27(7):489-493.

2. Kamiya K, Shimizu K, Kobashi H, Komatsu M, Nakamura A, Nakamura T, Ichikawa K. Clinical outcomes of posterior chamber toricphakic intraocular lens implantation for the correction of high myopic astigmatism in eyes with keratoconus: 6-month follow-up. Graefes Arch Clin Exp Ophthalmol 2011 Jul;249(7):1073-1080.

3. Venter J. Artisan phakic intraocular lens in patients with keratoconus. J Refract Surg 2009 Sep;25(9):759-764.

4. Kurian M, Nagappa S, Bhagali R, Shetty R, Shetty BK. Visual quality after posterior chamber phakic intraocular lens implantation in keratoconus. J Cataract Refract Surg 2012 Jun;38(6):1050-1057.

5. Leccisotti A, Fields SV. Angle-supported phakic intraocular lenses in eyes with keratoconus and myopia. J Cataract Refract Surg 2003 Aug;29(8):1530-1536.

6. Alió JL, Peña-García P, Abdulla GF, Zein G, Abu-Mustafa SK. Comparison of iris-claw and posterior chamber collagen copolymer phakic intraocular lenses in keratoconus. J Cataract Refract Surg 2014 Mar;40(3):383-394.

7. Kanellopoulos AJ, Binder PS. Collagen cross-linking with sequential topography-guided PRK; a temporizing alternative for keratoconus to penetrating keratoplasty. Cornea 2007 Aug;26(7):891-895.

8. Krueger RR, Kanellopoulos AJ. Stability of simultaneous topography-guided photorefractive keratectomy and riboflavin/UVA cross-linking for progressive keratoconus: case reports. J Refract Surg 2010 Oct;26(10):S827-S832. 
9. Kymionis GD, Kontadakis GA, Kounis GA, Portaliou DM, Karavitaki AE, Magarakis M, Yoo S, Pallikaris IG. Simultaneous topography-guided PRK followed by corneal collagen cross-linking for keratoconus. J Refract Surg 2009 Sep;25(9):S807-S811.

10. Kanellopoulos AJ. Comparison of sequential vs same-day simultaneous collagen cross-linking and topography-guided PRK for treatment of keratoconus. J Refract Surg 2009 Sep;25(9):S812-S818.

11. Stojanovic A, Zhang J, Chen X, Nitter TA, Chen S, Wang Q. Topography-guided transepithelial surface ablation followed by corneal collagen cross-linking performed in a single combined procedure for the treatment of keratoconus and pellucid marginal degeneration. J Refract Surg 2010 Feb;26(2):145-152.

12. Kanellopoulos AJ. Comparison of sequential vs same-day simultaneous collagen cross-linking and topography-guided PRK for treatment of keratoconus. J Refract Surg 2009 Sep;25(9):S812-S818.

13. Alhayek A, Lu PR. Corneal collagen crosslinking in keratoconus and other eye disease. Int J Ophthalmol 2015 Apr 18;8(2):407-418.

14. Güell JL, Morral M, Malecaze F, Gris O, Elies D, Manero F. Collagen cross-linking and toric iris-claw phakic intraocular lens for myopic astigmatism in progressive mild to moderate keratoconus. J Cataract Refract Surg 2012;38(3):475-484.

15. Alessio G, L'abbate M, Sborgia C, La Tegola MG. Photorefractive keratectomy followed by cross-linking versus cross-linking alone for management of progressive keratoconus: two-year follow-up. Am J Ophthalmol 2013;155(1):54-65.

16. Navas A, Tapia-Herrera G, Jaimes M, Graue-Hernández EO, Gomez-Bastar A, Ramirez-Luquín T, Ramirez-Miranda A. Implantable collamer lenses after intracorneal ring segments for keratoconus. Int Ophthalmol 2012 Oct;32(5):423-429.

17. Moshirfar M, Fenzl CR, Meyer JJ, Neuffer MC, Espandar L, Mifflin MD. Simultaneous and sequential implantation of intacs and verisysephakic intraocular lens for refractive improvement in keratectasia. Cornea 2011 Feb;30(2):158-163.

18. Denoyer A, Denoyer L, Marotte D, et al. Intraindividual comparative study of corneal and ocular wavefront aberrations after biaxial microincision versus coaxial small-incision cataract surgery. Br J Ophthalmol 2008;92(12):1679-1684.

19. Mojzis $P$, Piñero DP, Studeny $P$, et al. Comparative analysis of clinical outcomes obtained with a new diffractive multifocal toric intraocular lens implanted through two types of corneal incision. J Refract Surg 2011;27(9):648-657.

20. McMahon TT, Anderson RJ, Roberts C, et al. CLEK Study Group. Repeatability of corneal topography measurement in keratoconus with the TMS-1. Optom Vis Sci 2005;82(5):405-415.

21. Vinciguerra P, Munoz MI, Camesasca FI, Grizzi F, Roberts C. Long-term follow-up of ultrathin corneas after surface retreatment with phototherapeutic keratectomy. J Cataract Refract Surg 2005;31(1):82-87.

22. Alió JL, Piñero DP, Alesón A, Teus MA, Barraquer RI, Murta J, Maldonado MJ, Castro de Luna G, Gutiérrez R, Villa C, UcedaMontanes A. Keratoconus-integrated characterisation considering anterior corneal aberrations, internal astigmatism, and corneal biomechanics. J Catarct Refract Surg 2011;37(3):552-568.

23. Piñero DP, Alió JL, Tomás J, Maldonado MJ, Teus MA, Barraquer RI. Vector analysis of evolutive corneal astigmatic changes in keratoconus. Invest Ophthalmol Vis Sci 201;52(7):4054-4062.

24. Peña-García P. Vectorial analysis of astigmatic correction in stable keratoconus. PRK vs PIOLs. JCRS-2014-081, Version 1 (Sent).

\section{CATARACT SURGERY IN PATIENTS WITH KERATOCONUS}

Although some authors have indicated that cataract development in patients with keratoconus may occur quicker than in normal patients, ${ }^{1}$ there are very few studies in medical literature concerning this practice and the number of cases is very small.

A study was recently conducted on this topic within the framework of the RETICS which included the most cases described to date (17 eyes). ${ }^{2}$

The visual and refractive results were very encouraging. Safety and efficacy rates obtained were $1.38 \pm 0.58$ and $1.17 \pm 0.66$, respectively. Only one eye lost one line of corrected vision and $60 \%$ of eyes achieved uncompensated vision of $20 / 30$ or higher.

\subsection{Indications}

This surgery should be reserved for patients with stable keratoconus (see stability criteria described above); however, it may even be necessary in progressive patients if the visual impairment caused by the cataract is even more limiting than the corneal ectasia.

We recommend using lenses which may be inserted through microincision cataract surgery to cause the least possible alterations to the cornea. We suggest using the AcrySof IQ Toric lens by Alcon Laboratories because of the excellent results obtained in the study mentioned above. The spherical version can be used in the case of ectasia with corneal cylinders less than 1.50D.

We recommend using the SRK/T formula whenever possible. We, also, recommend taking special care when measuring the axial length, since readings can be affected by parallax errors caused by the cone. Results obtained were optimal for axial lengths of approximately $25 \mathrm{~mm}$. 
The use of multifocal lenses is not advised, because the keratoconic eye is already a multifocal eye. Adding multifocal lenses would lead to a very large number of foci with the consequent scattering of light in the ocular media.

\section{REFERENCES}

1. Piñero DP, Alió JL, Tomás J, Maldonado MJ, Teus MA, Barraquer RI. Vector analysis of evolutive corneal astigmatic changes in keratoconus. Invest Ophthalmol Vis Sci 201;52(7):4054-4062.

2. Garcia-Lledo M, Feinbaum C, Alió JL. Contact lens fitting in keratoconus. Compr Ophthalmol Update 2006 Mar-Apr;7(2):47-52.

\section{MONITORING KERATOCONUS PROGRESSION}

While early diagnosis of the disease is essential, as discussed at the beginning of this guide, monitoring the disease over time is just as important.

It is crucial to define the stage and rate of progression of this disease when making any decision regarding treatment.

We believe that to properly monitor the disease, a complete examination should be performed at least every 6 months. This examination should include all the diagnostic tests discussed above in section 2.1.

The importance of regular evaluation of the disease should also be stressed, because in its initial stages, good visual results can be obtained with soft contact lenses or, failing that, hard lenses (when the disease is at a later stage). ${ }^{1}$

As mentioned earlier, because the use of contact lenses is very common in these patients, this factor should be taken into account when establishing the protocol for regular examinations. ${ }^{2}$ These patients are advised not to wear contact lenses for at least 1 month in the case of hard lenses and 2 weeks in the case of soft lenses before any examination. This may not, however, be feasible, as patients are being deprived of their contact lenses, which is how they see best. As a result, we recommend a shorter period than that recommended and that this period be always the same.

This is due to the shaping effect that the lens has on the cornea. This effect may result in a sudden apparent improvement (although not an actual improvement) of the corneal profile if the patient does not stop wearing contact lenses for the mentioned time. This effect is obviously only temporary. In other words, it does not mean that the disease has improved with the use of contact lenses, because the underlying disease is still there.

The use of certain drugs and the presence of different eye diseases other than keratoconus (particularly allergyrelated diseases) should also be taken into account when performing any type of regular examination, since data may be altered.

In conclusion, we believe that, as with any degenerative disease, proper treatment is only possible when the disease is well monitored. Thus, clinicians will only be able to choose the best treatment (which as we have seen is quite variable depending on the patient) when they have the most detailed and up-to-date information possible at all times. Moreover, proper monitoring will guide us better in terms of patients' visual expectations and needs and will allow us to inform patients, whenever possible, about new developments or future perspectives for the treatment of their disease.

\section{REFERENCES}

1. Alió JL, Peña-García P, Fidan Abdulla GF, Soria FA, Zein G, Abu-Mustafa SK. MICS with toric intraocular lenses in keratoconus: outcomes and predictability analysis of postoperative refraction. Br J Ophthalmol 2014 Mar;98(3):365-370.

2. Garcia-Lledo M, Feinbaum C, Alió JL. Contact lens fitting in keratoconus. Compr Ophthalmol Update 2006 Mar-Apr;7(2):47-52. 